\title{
Infrared Absorption Spectra of Some Aldofuranoid, Aldopy- ranoid, and Acyclic 1-Acylamido Derivatives of Sugars
}

\author{
R. Stuart Tipson, Alberto S. Cerezo, ${ }^{1}$ Venancio Deulofeu, ${ }^{1}$ and Alex Cohen \\ Institute for Materials Research, National Bureau of Standards, Washington, D.C. 20234
}

(October 17, 1966)

\begin{abstract}
The infrared absorption spectra of two glycofuranosylacetamides and their perbenzoates, and of eleven glycopyranosylacylamides and eight esters thereof, are presented and discussed. For comparison, the spectra of thirteen 1,1-bis(acylamido)-1-deoxyalditols and eight esters thereof are also given and discussed.

The useful correlations between structure and infrared absorption made by Barker and co-workers for certain carbohydrates, and by Nanasi and co-workers for some $N$-arylglycosylamines, cannot be extended to the 1-acylamido compounds we have studied. Certain of Verstraeten's correlations may have some diagnostic value.
\end{abstract}

Key Words: Absorption spectra, acyclic sugars, l-acylamido sugars, aldofuranoid sugars, aldopyranoid sugars, infrared spectra.

\section{Purpose and Scope of the Project}

The main object of the present project was to record the infrared absorption spectra of a variety of 1-acylamido derivatives of sugars (having furanoid, pyranoid, or acyclic structures), in order to find whether previously reported correlations between the structure and specific bands in the infrared spectra of certain derivatives of sugars are also applicable to this group of compounds. In essence, the study consisted of answering two questions: (a) Do compounds having certain structural features show, in their infrared spectra, the bands previously described as characteristic of such features, and (b) do compounds that lack these structural features show or fail to show these bands in their infrared spectra? No infrared band can be regarded as unique for any feature, of course; and interpretation must be substantiated by other evidence.

The spectra have been recorded for two glycofuranosylacetamides and their perbenzoates; eleven glycopyranosylacylamides and eight esters thereof; and thirteen 1,1-bis(acylamido)-1-deoxyalditols and eight esters thereof. For this purpose, we used one of the small instruments now commercially obtainable, because such low-cost instruments are now customarily employed routinely as an analytical tool in practical organic chemistry.

\section{Compounds Investigated}

Table 1 gives a list of the compounds, their code numbers $[1],{ }^{2}$ and an index to the spectrograms; the serial number of a compound is the same as the number of its spectrogram.

In addition, a discussion is given of the spectra previously published [2] for five $N$-glycopyranosylacetamides and six acetates thereof, and for a 1,1-bis(acetamido)-1-deoxyalditol and its tetraacetate; the serial number given each of these compounds is that originally assigned [2], with the letter A suffixed thereto. Also, the spectra previously published [3] for three derivatives of D-ribosylamine have received consideration; the serial numbers for them are those originally given [3], with the letter B added.

The spectra were measured in the region of 4000 to $667 \mathrm{~cm}^{-1}$. The spectrograms of compounds 1 to 44 are given (see fig. 1), together with a discussion of (a) the structure of the compounds and (b) some of the outstanding features of their spectra. 
TABLE 1. Compounds measured and index to spectrograms

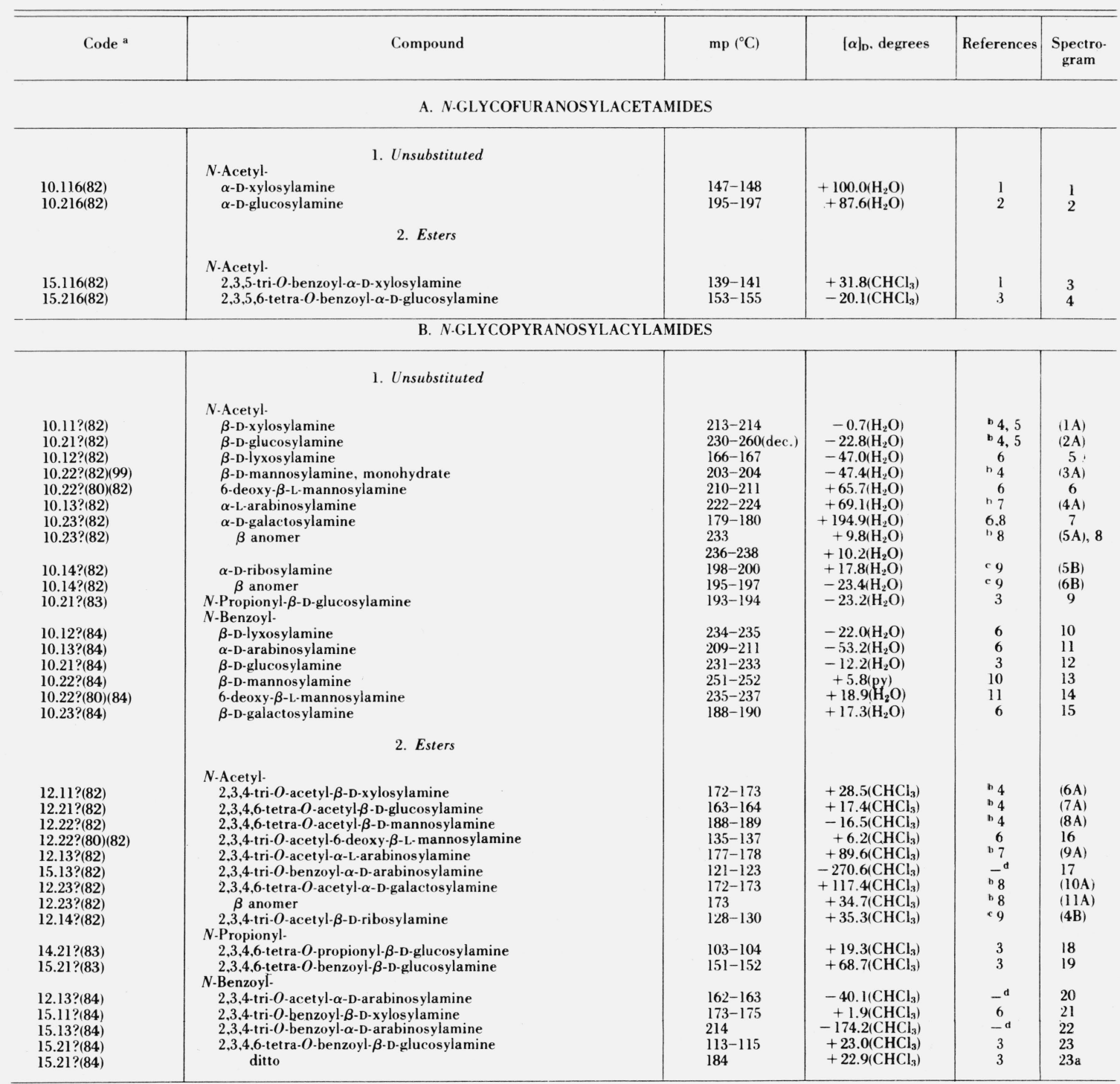

C. 1,1-BIS(ACYLAMIDO)-1-DEOXYALDITOLS

\begin{tabular}{|c|c|c|c|c|c|}
\hline & 1. Unsubstituted & & & & \\
\hline $10.027(52)(82)$ & $\begin{array}{l}\text { 1,1-Bis(acetamido)- } \\
\text { 1-deoxy-D-erythritol }\end{array}$ & $210-211$ & $+8.7\left(\mathrm{H}_{2} \mathrm{O}\right)$ & 12 & 24 \\
\hline $10.137(52)(82)$ & 1-deoxy-L-arabinitol & $189-191$ & $+9.8\left(\mathrm{H}_{2} \mathrm{O}\right)$ & b 13 & $(15 \mathrm{~A})$ \\
\hline $10.217(52(82)$ & 1-deoxy-D-glucitol & $165-167$ & $+4.0\left(\mathrm{H}_{2} \mathrm{O}\right)$ & 3 & 25 \\
\hline $10.227(52)(80)(82)$ & 1,6-dideoxy-L-mannitol & $238-240$ & $+22.7\left(\mathrm{H}_{2} \mathrm{O}\right)$ & 11 & 26 \\
\hline $10.237(52)(82)$ & 1-deoxy-D-galactitol & $194-196$ & $+8.4\left(\mathrm{H}_{2} \mathrm{O}\right)$ & 14 & 27 \\
\hline $10.217(56)(83)$ & $\begin{array}{l}\text { 1-Deoxy-1,1-bis(propionamido)-D-glucitol } \\
\text { l,1-Bis(benzamido). }\end{array}$ & $154-156$ & $+6.6\left(\mathrm{H}_{2} \mathrm{O}\right)$ & 3 & 28 \\
\hline $10.027(57)(84)$ & 1-deoxy-L-erythritol & $217-219$ & $+13.5(p y)$ & 15 & 29 \\
\hline $10.137(57)(84)$ & 1-deoxy-L-arabinitol & $194-196$ & $-5.3(\mathrm{py})$ & 15 & 30 \\
\hline $10.147(57)(84)$ & 1-deoxy-D-ribitol & $190-192$ & $-8.1(p y)$ & 15 & 31 \\
\hline $10.217(57)(84)$ & 1-deoxy-D-glucitol & $199-201$ & $+1.3(\mathrm{py})$ & 10 & 32 \\
\hline $10.217(57)(80)(84)$ & 1,2-dideoxy-D-arabino-hexitol & $208-210$ & $+12.0(\mathrm{py})$ & $-e$ & 33 \\
\hline $10.227(57)(84)$ & 1-deoxy-D-mannitol & $222-224$ & $+2.9(\mathrm{py})$ & 10,16 & 34 \\
\hline $10.227(57)(80)(84)$ & 1,6-dideoxy-L-mannitol & $220-222$ & $+14.1(\mathrm{py})$ & 11 & 35 \\
\hline & 1-deoxy-D-galactitol & $207-208$ & $-6.8(p y)$ & 14 & 36 \\
\hline
\end{tabular}




\begin{tabular}{|c|c|c|c|c|c|}
\hline $\begin{array}{l}12.137(52)(82) \\
12.217(52)(82) \\
\\
10.217(22)(57)(84) \\
12.127(22)(57)(84) \\
12.137(22)(57)(84) \\
15.137(57)(84) \\
12.027(57)(84) \\
12.147(57)(84) \\
12.217(57)(84)\end{array}$ & \begin{tabular}{l}
\multicolumn{1}{c}{ 2. Esters } \\
1,1-Bis(acetamido)-1-deoxy- \\
2,3,4,5-tetra- $O$-acetyl-L-arabinitol \\
2,3,4,5,6-penta- $O$-acetyl-D-glucitol \\
1,1-Bis(benzamido)-1-deoxy- \\
6-O-benzoyl-D-glucitol \\
2,3,4-tri- $O$-acetyl-5- $O$-benzoyl-D-lyxitol \\
2,3,4-tri- $O$-acetyl-5- $O$-benzoyl-D-arabinitol \\
2,3,4,5-tetra- $O$-benzoyl-D-arabinitol \\
2,3,4-tri- $O$-acetyl-L-erythritol \\
2,3,4,5-tetra- $O$-acetyl-D-ribitol \\
2,3,4,5,6-penta- $O$-acetyl-D-glucitol
\end{tabular} & $\begin{array}{l}218-219 \\
188-190 \\
\\
208-209 \\
184-186 \\
192-193 \\
134-136 \\
181-183 \\
175-176 \\
189-191 \\
\text { (needles) } \\
199-200 \\
\text { (plates) }\end{array}$ & $\begin{array}{l}-72.5\left(\mathrm{CHCl}_{3}\right) \\
+22.3\left(\mathrm{CHCl}_{3}\right) \\
\\
+5.2\left(\mathrm{py}^{2}\right. \\
+35.1\left(\mathrm{CHCl}_{3}\right) \\
+68.1\left(\mathrm{CHCl}_{3}\right) \\
+62.0\left(\mathrm{CHCl}_{3}\right) \\
+9.2\left(\mathrm{CHCl}_{3}\right) \\
-10.2\left(\mathrm{CHCl}_{3}\right) \\
-39.4\left(\mathrm{CHCl}_{3}\right)\end{array}$ & $\begin{array}{r}\mathrm{b} 5 \\
3 \\
\\
17 \\
18 \\
18 \\
15 \\
15 \\
15 \\
19\end{array}$ & $\begin{array}{l}(16 \mathrm{~A}) \\
37 \\
\\
38 \\
39 \\
40 \\
41 \\
42 \\
43 \\
44\end{array}$ \\
\hline
\end{tabular}

a In the coding system [1], certain numbers were left blank to permit later assignment to structural features as the need arose. The following additions have now been made: table 1, column 2, code No. 4, propionated; column 2, code No. 5, benzoylated; table 2, code No. 56, propionamido; code No. 57 , benzamido; code No. 83 , deoxypropionamido; code No. 84, benzamidodeoxy. ${ }^{b}$ Spectrum given in reference $5 .{ }^{\mathrm{c}}$ Spectrum given in reference 9 . ${ }^{\mathrm{d}}$ Prepared by A. S. Cerezo. $\mathrm{e}$ We thank deoxypropionamido; code No. 84, benzamidodeoxy.

References for Table

1. A. S. Cerezo and V. Deulofeu, Carbohydrate Res. 2,35 (1966).

2. R. C. Hockett and L. B. Chandler, J. Am. Chem. Soc. 66, 957 (1944).

3. A. S. Cerezo, S. Delpy, and V. Deulofeu, paper in preparation.

5. R. S. Tipson and H. S. Isbell, J. Res. NBS 65A (Phys. and Chem.) No. 1, 31 (1961).

6. S. Delpy, Ph.D. thesis, Buenos Aires, Argentina, 1962

7. H. S. Isbell and H. L. Frush, J. Res. NBS 46, 132 (1951) RP2186

8. H. L. Frush and H. S. Isbell, J. Res. NBS 47, 239 (1951) RP2248.

9. R. S. Tipson, J. Org. Chem. 26, 2462 (1961).

10. P. Brigl, H. Mühlschlegel, and R. Schinle, Ber. 64, 2921 (1931).

11. J. O. Deferrari and V. Deulofeu, J. Org. Chem. 22,802 (1957).

12. V. Deulofeu and J O Deferrari, Anales Assoc. Quim. Arg. 38,24l (1950).

13. H. S. Isbell and H . Frush J Am Chem Soe 71 1579 (1949).

14. J O. Deferrar and V. Deulofeu, J Org. Chem 17,1097 (1952)

15.

16. J. O. Deferrari and V. Deulofeu, J. Org. Chem. 17, 1093 (1952)

17. E. Gros, A. Lezerovich, E. F. Recondo, V. Deulofeu, and J. O. Deferrari, Anales Asoc. Quim. Arg. 50, 185 (1962).

18. E. R. de Labriola and V. Deulofeu, J. Org. Chem. 12, 726 (1947).

19. V. Deulofeu and J. O. Deferrari, J. Org. Chem. 17, 1087 (1952).

\section{Correlations Made by Barker and Co-workers}

\subsection{Description of the Correlations for Certain Aldopyranose Derivatives}

In a series of articles $[4,5,6]$, Barker and co-workers sought to identify, in the range of 960 to $730 \mathrm{~cm}^{-1}$, infrared bands characteristic of several aldopyranoses and their derivatives.

They expressed the frequency of a band as the mean and the standard deviation; although indication of a range is customary, their expression was used for defining the probable frequency of an absorption band shown by each of a set of compounds. However, it is not practical in the reverse process, namely, in searching for this band within a range of wavelengths in the spectrum of a single compound. For example, the value given for the type la band was $917+13 \mathrm{~cm}^{-1}$; this includes the interval of 930 to $904 \mathrm{~cm}^{-1}$, but it does not exclude the possibility that, for any one compound of this kind, the band might occur above $930 \mathrm{~cm}^{-1}$ or below $904 \mathrm{~cm}^{-1}$. Therefore, for each band sought in an individual spectrum, subsequent authors have, for practical purposes, apparently confined their attention to the interval obtained by adding the standard de- viation to, and subtracting it from, the mean value as given by these workers $[4,5,6]$.

\section{a. (D or L)-gluco Group Configuration}

In their first article [4], they recorded (in tables) the frequencies of various types of bands shown by D-glucopyranose derivatives; these bands are listed in table 2. From these results, they identified [4] "three principal sets of bands, for which the average values $\left(\mathrm{cm}^{-1}\right)$ and standard deviations" were (for $\alpha$ anomers) type $1 \mathrm{a}, 917 \pm 13$; type $2 \mathrm{a}, 844 \pm 8$; and type $3 \mathrm{a}, 766 \pm 10$; (for $\beta$ anomers) type $1 \mathrm{~b}, 920 \pm 5$; type $2 \mathrm{~b}$, $891 \pm 7$; and type $3 \mathrm{~b}, 774 \pm 9$. They found that the type $2 \mathrm{a}$ band can be used with considerable confidence for diagnosing the $\alpha$ anomeric form, particularly in polymers of glucopyranose. The type $2 \mathrm{~b}$ band was not found useful for diagnosing the $\beta$ anomeric form, but the absence of the type $2 \mathrm{a}$ band was considered very useful for diagnosing the $\beta$ anomeric form. They regarded the bands of types 1 and 3 as only useful for determining points of linkage in polymers of $\alpha$-glucopyranose.

TABLE 2. Frequencies ${ }^{\text {a }}\left(\mathrm{cm}^{-1}\right)$ of various types of bands for Dglucopyranose derivatives, as recorded in the tables in Ref. [4]

\begin{tabular}{l|r|r|r|r}
\hline \hline Linkage & Type 1 & Type 2a & Type 2b & Type 3 \\
\hline & & & & \\
$\boldsymbol{\alpha}$ Anomeric & $915 \pm 5$ & $847 \pm 6$ & & $767 \pm 8$ \\
Monosaccharides & $900 \pm 8$ & $842 \pm 7$ & & $751 \pm 8$ \\
& $930 \pm 9$ & $843 \pm 10$ & & $761 \pm 8$ \\
Higher saccharides & $917 \pm 2$ & $839 \pm 1$ & & $768 \pm 1$ \\
$\boldsymbol{\beta}$ Anomeric & $914 \pm 6$ & & $896 \pm 6$ & \\
Monosaccharides & b $918 \pm 5$ & & $891 \pm 8$ & c $772 \pm 9$ \\
Higher saccharides & $921 \pm 4$ & & $890 \pm 5$ & d $774 \pm 9$ \\
\hline
\end{tabular}

a Mean and standard deviation. " Six of ten compounds did not show this band. " Eleven of sixteen compounds did not show this band. "Five of sixteen compounds did not show this band. 
In a review, Neely [7] summarized this and related work; without explanation, he arrived at further conclusions, presumably in the following way. It would seem that, as the range for type la encompasses that for type $1 \mathrm{~b}$, the range $917 \pm 13 \mathrm{~cm}^{-1}$ may be simply referred to as type 1 (as shown in table 3). Also, as there is an overlap (from 776 to $765 \mathrm{~cm}^{-1}$ ) of $11 \mathrm{~cm}^{-1}$ for the ranges of types $3 \mathrm{a}(766 \pm 10)$ and $3 \mathrm{~b}(774 \pm 9)$, only extreme values of each range will have diagnostic value for these respective types, and so, they were combined (as $770 \pm 14 \mathrm{~cm}^{-1}$ ) and referred to as type 3 (see table 3 ).

TABLE 3. Summary of the results of Barker and co-workers [4,5] for infrared bands characteristic of five (D or L)-aldopyranoses and their derivatives

\begin{tabular}{|c|c|c|c|c|c|}
\hline \multirow{2}{*}{ Type } & \multicolumn{5}{|c|}{ Bands $\left(\mathrm{cm}^{-1} ;\right.$ mean and standard deviation, or range $)$} \\
\hline & Xylose & Arabinose & Glucose & Mannose & Galactose \\
\hline $\begin{array}{l}1 \\
2 \mathrm{c} \\
3\end{array}$ & $\stackrel{?}{-}$ & $\begin{array}{c}\text { andmers } \\
? \\
- \\
\text { c } 781-744\end{array}$ & $\begin{array}{c}\text { a } 917 \pm 13 \\
\text { b } \\
\text { a } 770 \pm 14 \\
\text { b } 753 \pm 17\end{array}$ & $\begin{array}{c}? \\
\text { b } 876 \pm 9 \\
\text { b } 791 \pm 18\end{array}$ & $\begin{array}{c}? \\
\text { b } 87 \dot{1} \pm 7 \\
\text { b } 752 \pm 20\end{array}$ \\
\hline $\begin{array}{l}2 a \\
3\end{array}$ & $\begin{array}{c}\boldsymbol{\alpha}_{-} \text {an } \\
\text { d } 749 \pm 10\end{array}$ & $\begin{array}{c}\text { mers only } \\
{ }^{c}-\end{array}$ & $\begin{array}{r}\text { a,e } 844 \pm 8 \\
\text { b } 843 \pm 4\end{array}$ & b $833 \pm 8$ & b $825 \pm 11$ \\
\hline $\begin{array}{l}2 \mathrm{a} \\
2 \mathrm{~b}\end{array}$ & ${ }_{-}^{\beta}$ an $^{-}$ & $\begin{array}{c}\text { ners only } \\
\text { d } 855-830 \\
\text { c } 854-836\end{array}$ & $\begin{array}{r}\text { a, e } 891 \pm 7 \\
\text { b } 890 \pm 8\end{array}$ & ${ }^{\mathrm{b}} 893 \pm 6$ & ${ }^{\mathrm{b}} 895 \pm 9$ \\
\hline
\end{tabular}

${ }^{\text {a }}$ Given in table 2 of ref. [7]: see present text for probable derivation. ${ }^{\mathrm{b}}$ Given in table 5 of ref. [5]. ${ }^{c}$ Given in table 4 of ref. [5]. " Given in the text of ref. [5]. ${ }^{\mathrm{e}}$ Given in the text of ref. [4].

In summary, in the correlations of Barker and coworkers [4], the infrared spectra of $\alpha$ - and $\beta$-(D or L)glucopyranose derivatives should show type 1 absorption $\left(917 \pm 13 \mathrm{~cm}^{-1}\right)$ and type 3 absorption (770 \pm 14 $\mathrm{cm}^{-1}$ ). In addition, the spectra of the $\alpha$ anomers should show type $2 \mathrm{a}$ absorption $\left(844 \pm 8 \mathrm{~cm}^{-1}\right)$, and the spectra of the $\beta$ anomers should show type $2 b$ absorption $\left(891 \pm 7 \mathrm{~cm}^{-1}\right)$. These values were given by Neely [7], in an article which will be discussed in section 3.2 .

If the bands are to have diagnostic value for glucopyranose derivatives, $\alpha$ anomers should not show type $2 \mathrm{~b}$ absorption, and $\beta$ anomers should not show type 2a absorption. However, these workers [4] found that (a) some $\alpha$ anomers exhibited type 1 absorption in the range of type $2 \mathrm{~b}$ bands, and (b) some $\beta$ anomers showed "weak peaks of type $2 a$ " which they believed were due to traces of the $\alpha$ anomers.

Barker and co-workers [4] then made tentative assignments for these glucopyranose derivatives. They suggested that: (1) type 1 bands might be due to a ring vibration including ring C-O-C antisymmetrical stretching; (2) type 2 bands might be connected with "one of the C-H deformation modes in which the hydrogen on C-1 is involved intimately"; and (3) type 3 bands might be correlated with ring breathing.
In a second article, Barker and co-workers [5] examined the infrared spectra of some more glucopyranose derivatives, and found slightly different positions for bands of type $2 \mathrm{a}$ and type 3 (see table 3 ). As before, some of the $\alpha$ anomers were found to show type 1 absorption in the range of type $2 \mathrm{~b}$ bands. Also, they pointed out that derivatives containing a benzene ring may show absorption in the region of the type $2 \mathrm{a}$ band, and that acetates absorb in the region of the type $2 \mathrm{~b}$ band.

\section{b. Other Group Configurations}

The results of Barker and co-workers [5] for infrared bands characteristic of four other pyranoid aldoses and their derivatives are also summarized in table 3.

No decision was made as to the presence or absence of bands of type 1 in the spectra of these other compounds. It was found that, for manno- and galactopyranose, the type $2 a$ band can be used for diagnosing the $\alpha$ anomeric form, although with slightly less confidence than for $\alpha$-glucopyranose derivatives. Absence of the type $2 \mathrm{a}$ band was useful for diagnosing the $\beta$ anomeric form.

These authors [5] also found that a band at $876 \pm 9$ $\mathrm{cm}^{-1}$, designated type $2 c$, was characteristic of mannopyranose derivatives; and that a band of type $2 \mathrm{c}$, at $871 \pm 7 \mathrm{~cm}^{-1}$, was characteristic of galactopyranose derivatives.

From these results (see table 3), it may be seen that the mean frequency for a given type of absorption may change with the group configuration; for example, the mean frequency for type 3 absorption is at $791 \mathrm{~cm}^{-1}$ for the manno configuration, but at 752 to $753 \mathrm{~cm}^{-1}$ for the gluco and galacto configurations. Furthermore, $\beta$-(D or L)-xylopyranose derivatives are not characterizable by any of the bands listed in table 3 . In connection with the present study, it should be noted that many derivatives containing a benzene ring absorb [8] in the region of the type 3 band of the glucopyranose, galactopyranose, and $\alpha$-xylopyranose derivatives.

Barker and co-workers suggested that type $2 a$ bands may be associated with an equatorial C- $1-\mathrm{H}$ grouping, because the favored conformation ${ }^{3}$ (CA) of the $\alpha-(\mathbf{D}$ or L) anomers having the gluco, manno, and galacto configurations has an equatorially attached hydrogen atom on C-1. (However, for both the manno and galacto configurations, some $\beta$ anomers showed type $2 \mathrm{a}$ absorption.) The type $2 \mathrm{a}$ absorption for $\beta$-(D or L)-arabinopyranose (see table 3 ) was related to the same structural feature, because the CE conformation (having an equatorially attached hydrogen atom on $\mathrm{C}-1$ of the $\beta$ anomer) is favored for the arabino configuration. Similarly, type $2 b$ bands, shown by the $\beta$-(D or L) anomers of gluco-, manno-, and galactopyranose, were associated with the presence of an axial C-1 - H grouping.

\footnotetext{
${ }^{3}$ In the conformational nomenclature of Isbell and Tipson [9], the $\beta$ anomer af a pyranoid aldose in the CA conformation has an axial C-1-H bond; in the CE conformation, it has an equatorial $\mathrm{C}-1-\mathrm{H}$ bond.
} 
Barker and co-workers [5] again made assignments for these bands. They suggested that the type $2 c$ bands are due to deformations of the equatorial $\mathrm{C}-\mathrm{H}$ bond at $\mathrm{C}-2$ of (D or $\mathrm{L}$ )-mannopyranose-CA and at C-4 of (D or L)-galactopyranose-CA. In agreement with this conclusion, Ellis [10] has found that derivatives of (D or L)-arabinopyranose-CE show type 2c absorption. However, according to Ellis, "an equatorial $\mathrm{C}-\mathrm{H}$ bond at $\mathrm{C}-3$ may also give rise to the type 2 c absorption," as in derivatives of (D or L)-ribopyranose-CA. Barker and co-workers indicated that $\beta$-(D or $\mathrm{L}$ )-xylopyranose derivatives show no absorption of type 3, and that, in the CA conformation, these derivatives have all of the exocyclic $\mathrm{C}-\mathrm{O}$ bonds equatorial; $\beta$-(D or L)-glucopyranose derivatives showed weak absorption of type 3 , and their CA conformation has an equatorial hydroxymethyl group on C-5. If type 3 absorption is a symmetrical ring-breathing frequency, such a band would not be expected to be strong for the more symmetrical molecules, such as $\beta$-D-xylo- and $\beta$-D-gluco-pyranose, but would be expected to be stronger for the corresponding $\alpha$ anomers (having a bulky group attached axially at C-1). Their assignments for the bands of types $2 a$ and $2 b$ have since been disproved [11], but the correlations, already mentioned, remain unaffected. It was "concluded that a vibration of the whole grouping at C-1 is responsible for type $2 \mathrm{a}$ and type $2 \mathrm{~b}$ absorption. The frequency exhibited is dependent on the stereochemical configuration at C-1 (i.e., $\alpha$ or $\beta$ )."

Barker and co-workers [6] next found that 2-deoxy and 3-deoxy derivatives of gluco-, manno-, and galactopyranose show absorption at $867 \pm 2 \mathrm{~cm}^{-1}$, attributed to a $\mathrm{CH}_{2}$ rocking mode of a ring-methylene grouping not adjacent to the ring-oxygen atom (because xylopyranose derivatives, having a methylene grouping at C-5 do not show this band). In addition, they noted that seven 6-deoxy derivatives of mannopyranose or galactopyranose show a band near $967 \mathrm{~cm}^{-1}$, tentatively attributed to a $C$-methyl (terminal) rocking mode, but they cautioned that this band might not have diagnostic value.

Application of the correlations of Barker and coworkers $[4,5,6]$ has proved useful in the study of many related compounds, including oligo- and poly-saccharides; and, for the compounds they studied, none of their correlations are questioned in the present article.

TABLE 4. Ranges ${ }^{\text {a }}\left(\mathrm{cm}^{-1}\right)$ for the bands of types $2 a$ ard $2 b$, as given by Spedding [13] from the work of Barker and co-workers [12]

\begin{tabular}{c|c|c|c|c}
\hline \hline Type & Anomer & Glucopyranose & Mannopyranose & Galactopyranose \\
\hline 2a & $\alpha$ & ${ }^{\mathrm{b}} 855-833(844)$ & $\mathrm{b} 843-818(831)$ & $\mathrm{b} 839-810(825)$ \\
$2 \mathrm{~b}$ & $\beta$ & ${ }^{\mathrm{c}} 905-876(891)$ & $\mathrm{d} 898-888(893)$ & $\mathrm{d} 914-886(900)$ \\
\hline
\end{tabular}

${ }^{a}$ The mean is given in parentheses. ${ }^{b}$ Derivatives containing a benzene ring absorb here. ${ }^{\mathrm{c}}$ Must be confirmed by absence of absorption at $855-833 \mathrm{~cm}^{-1}$. ${ }^{\mathrm{d}}$ But other types of vibration also occur here.

These results were collated by Barker and coworkers [12]. Some of them were summarized by
Spedding [13], who gave slightly different figures for the ranges of absorption for the bands of types $2 \mathrm{a}$ and $2 \mathrm{~b}$, as shown in table 4 . He also stated that $\beta$-arabinopyranose derivatives show a type 2a band at 855 to $830 \mathrm{~cm}^{-1}$ (mean, $843 \mathrm{~cm}^{-1}$ ); and that $\alpha$-xylopyranose derivatives show a band at 760 to $740 \mathrm{~cm}^{-1}$ (mean, $750 \mathrm{~cm}^{-1}$ ), but that many derivatives containing a benzene ring absorb here.

\subsection{Neely's Summation}

In a review [7], Neely correctly described the results of Barker and co-workers in the text of his article, and he attempted to condense this information in his table II (reproduced in table 5) entitled "Frequencies Characteristic of the Sugar Pyranose Ring." Study of this table reveals that, of the seven vibrations listed in column 1, only the first two could be described as possibly being "frequencies characteristic of the sugar pyranose ring." The other bands are those indicated by Barker and co-workers $[4,5,6]$ to be characteristic of certain structural features possessed by some compounds that have a pyranoid ring. Unfortunately, Neely's table II has since been copied in articles and books [14].

TABLE 5. Frequencies characteristic of the sugar pyranose ring ${ }^{\text {a }}$

\begin{tabular}{l|c|c}
\hline \hline \multicolumn{1}{c|}{ Group } & Frequeney & References $^{\mathrm{b}}$ \\
\hline & & \\
& $\mathrm{cm}^{-1}$ & \\
Antisymmetrical ring vibration & $917 \pm 13$ & {$[4]$} \\
Symmetrical ring breathing vibration & $770 \pm 14$ & {$[4]$} \\
$\alpha$-Anomeric C-H deformational vibration & $844 \pm 8$ & {$[4]$} \\
$\beta$-Anomeric C-H deformational vibration & $891 \pm 7$ & {$[4]$} \\
Equatorial C-H deformational vibration, & $880 \pm 8$ & {$[5]$} \\
other than anomeric C-H & $867 \pm 2$ & {$[6]$} \\
Ring methylene rocking vibration & $967 \pm 6$ & {$[6]$} \\
Terminal methyl group rocking vibration & $967 \pm 6$ & \\
\hline
\end{tabular}

a According to W. B. Neeley [7]. ' ${ }^{\mathrm{b}}$ The reference numbers have been changed to those used in the present article.

The $2 \mathrm{a}$ band was described in table 5 as due to an " $\alpha$-anomeric $\mathrm{C}-\mathrm{H}$ deformational vibration"; however, Spedding more correctly described it as caused by an "anomeric $\mathrm{C}-\mathrm{H}$ equatorial deformation" [15], because Barker and co-workers [12] had indicated that, in the favored chair conformation (CE) of (D or L)-arabinopyranose derivatives, the $\beta$ anomers have an equatorial $\mathrm{C}-1-\mathrm{H}$ bond. As already mentioned, further work [11] has shown that all that can at present be said is that type $2 \mathrm{a}$ bands are in some way associated with structures having an equatorial $\mathrm{C}-1-\mathrm{H}$ bond, and type $2 \mathrm{~b}$ bands with those having an axial $\mathrm{C}-\mathrm{l}-\mathrm{H}$ bond.

It is evident that the bands of types $2 a$ and $2 b$, listed in table 5 as occurring at $844 \pm 8 \mathrm{~cm}^{-1}$ and at $891 \pm 7 \mathrm{~cm}^{-1}$, were taken from the paper [4] which had been restricted to study of D-glucopyranose and its derivatives. However, Neely may have considered that these values also applied fairly well to other pyranoses; because, for the gluco-, manno-, and galacto-pyranose derivatives (see table 3 ), the ranges of 852 to $814 \mathrm{~cm}^{-1}$ (mean, $833 \mathrm{~cm}^{-1}$ ) and 904 to 882 $\mathrm{cm}^{-1}$ (mean, $893 \mathrm{~cm}^{-1}$ ) encompass the values given [5] for the $2 \mathrm{a}$ and $2 \mathrm{~b}$ bands, respectively, of these three groups of sugars. Moreover, as pointed out by Barker 
and co-workers [5], the range of 855 to $830 \mathrm{~cm}^{-1}$ (mean, $843 \mathrm{~cm}^{-1}$ ) for the $\beta$-arabinopyranose derivatives (see table 3 ) fits the value for the $2 \mathrm{a}$ band.

As regards the bands of types 1 and 3, we have already discussed (in sec. 3.1a) how Neely [7] must have derived the values that he lists as occurring at $917 \pm 13 \mathrm{~cm}^{-1}$ and at $770 \pm 14 \mathrm{~cm}^{-1}$ - namely, from the values given [4] for D-glucopyranose derivatives. Barker and co-workers [5] had reached no firm conclusion as to the presence of type $l$ bands in the spectra of any pyranoid sugar derivatives other than those of (D or L)-glucopyranose. However, it would appear that, without comment, Neely may have intended to include bands of mannopyranose and galactopyranose derivatives in these values. Inspection of columns 2 and 3 of table 3 in Ref. [5] reveals that all of the mannopyranose compounds show a type 1 band in the range of 947 to $905 \mathrm{~cm}^{-1}$ (mean, $926 \mathrm{~cm}^{-1}$ ); similarly, twelve of the 14 galactopyranose compounds (columns 1, 2, and 3 of table 2 in Ref. [5]) show a band in the range of 943 to $905 \mathrm{~cm}^{-1}$ (mean, $924 \mathrm{~cm}^{-1}$ ). For the type 3 bands listed for these three hexopyranoses in our table 3 , the range is 809 to $732 \mathrm{~cm}^{-1}$ (mean, $771 \mathrm{~cm}^{-1}$ ); Neely [7] listed $770 \pm 14 \mathrm{~cm}^{-1}$, and presumably concluded that this value should serve for derivatives of the three hexopyranoses. As derivatives of $\beta$-(D or L)xylopyranose do not show type 3 absorption [5], this band cannot be ascribed to the pyranoid ring per se.

The band of type $2 c$, given in table 5 as lying at $880 \pm 8 \mathrm{~cm}^{-1}$, was presumably derived by Neely [7] from the values given by Barker and co-workers [5] for manno- and galacto-pyranose derivatives, namely, $876 \pm 9 \mathrm{~cm}^{-1}$ and $871 \pm 7 \mathrm{~cm}^{-1}$; it was indicated that this band is shown by conformers having an equatorial $\mathrm{C}-\mathrm{H}$ bond (other than an equatorial, anomeric $\mathrm{C}-\mathrm{H}$ bond).

Finally, Neely [7] indicated that the last two bands listed in his table II were taken from a paper by Barker and co-workers [6]. The band at $867 \pm 2 \mathrm{~cm}^{-1}$ had been found for 2-deoxy derivatives of gluco- and galacto-pryanoses and for a 3-deoxy derivative of mannopyranose. The band at $967 \pm 6 \mathrm{~cm}^{-1}$ had been found for 6-deoxy derivatives of manno- and galactopyranoses.

\subsection{Description of the Correlations for Aldo- and Keto-furanose Derivatives}

For aldo- and keto-furanose derivatives, Barker and Stephens [16] noted absorption bands as follows: type A, $924 \pm 13 \mathrm{~cm}^{-1}$ ("not distinguished from types 1 or 2 b" of aldopyranoses); and type D, 799 $\pm 17 \mathrm{~cm}^{-1}$. "In addition, most of these compounds also showed type $\mathrm{B}$ absorption at $879 \pm 7 \mathrm{~cm}^{-1}$ and type $\mathrm{C}$ at $858 \pm 7 \mathrm{~cm}^{-1}$." Type A absorption was assigned to the symmetrical ring-breathing frequency. The following tentative assignments were also made: type $\mathrm{D}$, to a carbon-hydrogen deformation mode where the hydrogen atom is on a carbon atom directly attached to the ring-oxygen atom; and types $\mathrm{B}$ and $\mathrm{C}$, to modes of vibration involving the skeletal stretching of the substituents, with type B possibly concerned with side chains and type C "with the $\mathrm{OH}$ group."

\subsection{Attempted Application of These Correlations to 1-Acylamido Derivatives}

In this part of our study, the objective was not to make assignments for the bands observed in the spectra, but to determine whether the bands of the types reported by Barker and co-workers $[4,5,6,16]$ have diagnostic value for sugar derivatives other than those studied by these investigators. That is, we wished to find out if, when a 1-acylamido group is present in the molecule, the presence or absence of these bands can still be correlated with those structural features mentioned by Barker and co-workers.

For example, absorption of type A has been assigned to the symmetrical ring-breathing frequency of the furanoid ring. Consequently, it is to be expected that the spectrum of every furanoid compound having ringbreathing should show a band of type A. If the spectrum of a furanoid compound does not show a band of type A, either the ring-breathing is disturbed (or suppressed) or the correlation is faulty. However, if the spectrum of a nonfuranoid compound shows a band of type A, the correlation is still valid, but its diagnostic value is impaired because it is no longer exclusive, but merely indicative of a possibility that must then be checked by some other test.

To make this study, we examined, in turn, the spectra of those cyclic 1-acylamido derivatives having the five configurations given in table 3 , because these were the only configurations discussed by Barker and coworkers for pyranoid derivatives. For comparison, we also examined the spectra of related acyclic derivatives, where available.

Table 6 lists the bands for compounds having the xylo configuration, from which it may be seen that the furanoid compounds 1 and 3 show some bands that have been associated [16] with the furanoid $(f)$ structure, but they also show some bands that have been ascribed to the pyranoid $(p)$ structure. The type $3(\alpha)$ band of compound 3 might be due to the benzene ring. The pyranoid compounds show some $p$ bands, and also some $f$ bands. Pyranoid compound lA shows one $f$ and one $p$ band. The $\beta$ compounds $1 \mathrm{~A}$ and 21 lack type $2(\beta)$ absorption, and the $\beta$ compound $6 \mathrm{~A}$ shows type $3(\alpha)$ absorption. The type $2(\beta)$ band shown by compound $6 \mathrm{~A}$ (the only acetate ester) might be due to the acetate ester groups. The pyranoid compound 21 shows all of the $f$ bands, and also a band in the 855 to $830 \mathrm{~cm}^{-1}$ region (a region where the xylopyranose compounds studied by Barker and co-workers [5] show no absorption) which could be due to the benzene ring. The three pyranoid compounds (1A, 6A, and 21) show type 1 absorption; this was not specifically recognized by Barker and co-workers [5] for xylopyranose compounds, although they recorded bands in this region (in table 4 of ref. [5]) for such compounds. 
TABLE 6. Bands $\left(\mathrm{cm}^{-1}\right)^{\mathrm{a}}$ in the spectra of compounds having the xylo configuration

\begin{tabular}{|c|c|c|c|c|c|c|c|c|c|}
\hline \multirow{4}{*}{$\begin{array}{l}\text { Serial } \\
\text { No. }\end{array}$} & \multirow{4}{*}{ Anomer } & \multicolumn{4}{|c|}{$f$ bands } & \multicolumn{4}{|c|}{$p$ bands } \\
\hline & & A & B & C & D & 1 & $2(\beta)$ & No band & $3(\alpha)$ \\
\hline & & \multicolumn{7}{|c|}{ Range } & \\
\hline & & 937-911 & 886-872 & $865-851$ & $816-782$ & 930-904 & $896-886$ & $855-830$ & 759-739 \\
\hline $\begin{array}{c}\text { Furanoid } \\
1 \\
3\end{array}$ & $\begin{array}{l}\alpha \\
\alpha\end{array}$ & (938) & $\begin{array}{c}883 \\
(887,871)\end{array}$ & $\frac{-}{860}$ & $\begin{array}{l}803 \\
810\end{array}$ & (903) & $\bar{b}[\overline{887}]$ & 831 & $\overline{749}$ \\
\hline $\begin{array}{c}\text { Pyranoid } \\
\text { 1A } \\
6 \mathrm{~A} \\
21\end{array}$ & $\begin{array}{l}\beta \\
\beta \\
\beta\end{array}$ & $\begin{array}{c}(939) \\
934 \\
(939)[913]\end{array}$ & $\begin{array}{c}- \\
877 \\
(870)\end{array}$ & $\frac{-}{[853]}$ & $\begin{array}{l}\overline{-} \\
805\end{array}$ & $\begin{array}{l}(903) \\
904 \\
913\end{array}$ & $\begin{array}{l}- \\
895 \\
-\end{array}$ & $\begin{array}{l}\overline{-} \\
\overline{853}\end{array}$ & $\overline{(738)}$ \\
\hline
\end{tabular}

${ }^{a}$ Enclosure of a wavenumber in parentheses indicates that it is located somewhat (usually not more than $3 \mathrm{~cm}^{-1}$ ) beyond the upper or lower limit of the wavenumber range under consideration. ${ }^{b}$ Enclosure of a wavenumber in brackets indicates that, from other evidence, an alternative and more likely assignment can be made. The wavenumber for the latter is not enclosed in brackets.

Table 7 lists six pyranoid compounds and five acyclic compounds having the arabino configuration. Four of the $\alpha$ anomers show type $2(\beta)$ absorption, and these four compounds have a benzene ring. All of the pyranoid compounds show type 1 absorption; this was not specifically recognized by Barker and co-workers [5] for arabinopyranose compounds, although they recorded bands in this region (in table 4 of ref. [5]) for such compounds. However, the pyranoid compounds also show some $f$ bands; indeed, compounds 11, 20, and 22 show all of the $f$ bands (as well as the $p$ bands). The acyclic compounds show some $f$ and $p$ bands. Compounds 16A and 40 show all of the $f$ and $p$ bands; and compounds 30 and 41 show all of the $p$ bands. Like many furanoid compounds studied by Barker and co-workers [16], the acyclic compounds 30 and 41 show types A and D absorption, but lack type B (compound 41) or type C (compound 30) absorption.

TABLE 7. Bands $\left(\mathrm{cm}^{-1}\right)^{\mathrm{a}}$ in the spectra of compounds having the arabino configuration

\begin{tabular}{|c|c|c|c|c|c|c|c|c|}
\hline \multirow{4}{*}{$\begin{array}{c}\text { Serial } \\
\text { No. }\end{array}$} & \multirow{4}{*}{ Anomer } & \multicolumn{4}{|c|}{$f$ bands } & \multicolumn{3}{|c|}{$p$ bands } \\
\hline & & A & B & C & D & 1 & $2(\beta)$ & $3(\alpha ; \beta)$ \\
\hline & & \multicolumn{7}{|c|}{ Range } \\
\hline & & $937-911$ & $886-872$ & $865-851$ & $816-782$ & $930-904$ & $855-830$ & $781-744$ \\
\hline \multirow{7}{*}{$\begin{array}{c}\text { Pyranoid } \\
4 \mathrm{~A} \\
11 \\
9 \mathrm{~A} \\
17 \\
20 \\
22\end{array}$} & & & & & & & & \\
\hline & $\alpha$ & 936[913] & - & 864 & - & 913 & - & 771 \\
\hline & $\alpha$ & $934[928]$ & 880 & [856] & 803 & 928 & (856) & 780 \\
\hline & $\alpha$ & 933 & (870) & - & - & 907 & - & (741) \\
\hline & $\alpha$ & $935[931]$ & - & 862 [851] & 806 & (931) & 851 (828) & 774,758 \\
\hline & $\alpha$ & {$[931,917]$} & 876 & {$[851]$} & 808 & (931) 917 (1) & 7 7) 851 & 746 \\
\hline & $\alpha$ & 937 & 877 & [851] & 804 & $(901)$ & 851 & 772,752 \\
\hline \multicolumn{9}{|l|}{ Acyclie } \\
\hline $15 \mathrm{~A}$ & - & - & 877 & - & - & 904 & - & 775 (742) \\
\hline 30 & - & 919 & (870) & - & 800 & 919 & 845 & 770 \\
\hline $16 \mathrm{~A}$ & - & 931,922 & 873 & 856 & 784 & 922 & $(856)$ & (784) \\
\hline 40 & - & (939) 932, & 873 & 855 & 808,800 & (932) 921 & $855(829)$ & $772(?)$ \\
\hline 41 & - & $\begin{array}{c}921,911 \\
(938) 933, \\
911\end{array}$ & - & $867) 851$ & 805,801 & $\begin{array}{c}911 \\
(933) 911\end{array}$ & $\begin{array}{c}851,846, \\
840\end{array}$ & (743) \\
\hline
\end{tabular}

a See footnotes to table 6.
In table 8 are listed the bands of furanoid and pyranoid compounds having the gluco configuration, together with those of seven related acyclic compounds. The furanoid compounds show the $f$ bands, although the type B band could be interpreted as being a $p$ band of type $2(\beta)$; hence, these compounds fit the correlations of Barker and co-workers [16]. With the possible exception of compound $2 \mathrm{~A}$, the pyranoid compounds do not show a type 3 band, but all of them show a type 1 band. Although all of the pyranoid compounds are $\beta$ anomers, four of them do not show type $2(\beta)$ absorption, and three show type $2(\alpha)$ absorption; compound 18 shows both. Compound 23a, which is formed on melting compound 23 at 117$120^{\circ}$ and allowing the melt to crystallize, shows only one $p$ band, at $922 \mathrm{~cm}^{-1}$; this could equally well be interpreted as being an $f$ band of type $\mathrm{A}$, in which case the compound shows no $p$ bands, but all of the $f$ bands; this could suggest the possibility that it is the furanoid isomer of compound 23, which shows the ease with which such bands could be misinterpreted. The pyranoid compound $2 \mathrm{~A}$ shows no $f$ bands, and compound 9 shows an $f$ band of type $2 \mathrm{~A}$ which might well be a $p$ band of type 1 ; these are in agreement with the correlations. The rest of the pyranoid compounds show two or more $f$ bands, and compounds 18 and $23 \mathrm{a}$ show all of them. The acyclic compounds show $f$ and $p$ bands. Compounds 32 and 38 show all of the bands of both sorts; compounds 33 and 44 show all of the $f$ bands; and compound 37 shows all of the $p$ bands.

For pyranoid compounds having the manno configuration (see table 9), all of the $\beta$ anomers show type 1 and $2(\beta)$ bands. The $\beta$ anomers 13 and 14 show a type $2(\alpha)$ band at the extremes of the range, which could be due to the benzene ring (not present in the four others). Also, the pyranoid compounds show some $f$ bands; however, some of the ranges given by Barker and co-workers [16] for $f$ bands could also be interpreted as being $p$ bands in the case of manno- 
TABLE 8. Bands $\left(\mathrm{cm}^{-1}\right)^{\text {a }}$ in the spectra of compounds having the gluco configuration

\begin{tabular}{|c|c|c|c|c|c|c|c|c|c|c|}
\hline \multirow{4}{*}{$\begin{array}{l}\text { Serial } \\
\text { No. }\end{array}$} & \multirow{4}{*}{ Anomer } & \multicolumn{4}{|c|}{$f$ bands } & \multicolumn{5}{|c|}{$p$ bands } \\
\hline & & A & B & C & D & $1(\alpha ; \beta)$ & $2(\beta)$ & $2(\alpha)$ & \multicolumn{2}{|c|}{$3(\alpha ; \beta)$ or $3(\alpha ; \beta)$} \\
\hline & & \multicolumn{9}{|c|}{ Range } \\
\hline & & $937-911$ & $886-872$ & $865-851$ & $816-782$ & $930-904$ & $898-882$ & $852-836$ & $784-756$ & $770-736$ \\
\hline$\underset{2}{\text { Furanoid }}$ & & & & & & & & & & \\
\hline 4 & $\alpha$ & $\begin{array}{l}(942) \\
(939)\end{array}$ & $\begin{array}{l}886 \\
885\end{array}$ & $\begin{array}{l}867) \\
857\end{array}$ & $\begin{array}{l}810,794 \\
803,800\end{array}$ & - & {$[886]$} & $\overline{-}$ & $\overline{776}$ & $\overline{-}$ \\
\hline Pyranoid & & & & & & & & & & \\
\hline $2 \mathrm{~A}$ & $\beta$ & {$[\overline{2} 2]$} & - & - & - & (902) & - & - & (758?) & (758?) \\
\hline 12 & $\beta$ & [917] & {$[(889)]$} & $(\overline{866})$ & $8 \overline{11}$ & $\begin{array}{c}922,908 \\
917\end{array}$ & $\begin{array}{l}896 \\
889\end{array}$ & $\overline{-}$ & - & $=$ \\
\hline $7 \mathrm{~A}$ & $\beta$ & [917] & (871) & - & - & 917,909 & 897 & - & - & $=$ \\
\hline 18 & $\beta$ & 934 & [886] & 864 & 810 & 905 & 886 & 836 & - & - \\
\hline 19 & $\beta$ & $\begin{array}{c}(940) \\
{[(910)]}\end{array}$ & - & 858 & 803 & 910. & - & 847 & - & - \\
\hline 23 & $\beta$ & $\begin{array}{l}(940) \\
{[(907)]}\end{array}$ & - & 858 & 804 & 907 & - & 845 & - & - \\
\hline $23 \mathrm{a}$ & $\beta$ & (940) 922 & 874 & 855 & 806 & [922] & - & - & - & - \\
\hline Acyclic & & & & & & & & & & \\
\hline $\begin{array}{l}25 \\
28\end{array}$ & - & 930 & 882 & - & 787 & 930,909 & 882 & - & 756 & 756 \\
\hline $\begin{array}{l}28 \\
32\end{array}$ & - & $\begin{array}{l}926 \\
923\end{array}$ & $\overline{878}$ & $\begin{array}{l}864 \\
862\end{array}$ & $\begin{array}{l}795 \\
800\end{array}$ & $\begin{array}{l}926,909 \\
923\end{array}$ & $\begin{array}{l}894 \\
892\end{array}$ & 847 & $\overline{775}$ & - \\
\hline 33 & - & 930 & 877 & 863,853 & 810,804 & 930 & $\begin{array}{l}892 \\
889\end{array}$ & (853) & - & - \\
\hline 37 & - & $\begin{array}{l}937,925, \\
917\end{array}$ & - & $862(850)$ & - & 925,917 & 897 & 850 & 760 & 760 \\
\hline $\begin{array}{l}38 \\
44\end{array}$ & - & $\begin{array}{c}929 \\
935,917\end{array}$ & $\begin{array}{l}(870) \\
(887)\end{array}$ & $\begin{array}{l}(849) \\
(868)\end{array}$ & $\begin{array}{c}810,801 \\
808\end{array}$ & $\begin{array}{l}929 \\
917\end{array}$ & $\left(\begin{array}{l}901) \\
887\end{array}\right.$ & 849,842 & 760 & 760 \\
\hline & & & & & & & & & & (7/2) \\
\hline
\end{tabular}

a See footnotes to table 6 .

TABLE 9. Bands $\left(\mathrm{cm}^{-1}\right)^{\mathrm{a}}$ in the spectra of compounds having the manno configuration

\begin{tabular}{|c|c|c|c|c|c|c|c|c|c|c|c|}
\hline \multirow{4}{*}{$\begin{array}{l}\text { Serial } \\
\text { No. }\end{array}$} & \multirow{4}{*}{ Anomer } & \multicolumn{4}{|c|}{$f$ bands } & \multicolumn{6}{|c|}{$p$ bands } \\
\hline & & A & B & C & D & $5-C-\mathrm{CH}_{3}$ & 1 & $2(\beta)$ & $2 \mathrm{c}(\alpha ; \beta)$ & $2(\alpha)$ & $3(\alpha ; \beta)$ \\
\hline & & \multicolumn{10}{|c|}{ Range } \\
\hline & & 937-911 & $886-872$ & $865-851$ & 816-782 & $973-961$ & 930-904 & 899-887 & $885-867$ & $841-825$ & 809-773 \\
\hline Pyranoid & & & & & & & & & & & \\
\hline & $\beta$ & - & [876] & - & {$[808]$} & - & 907 & (900) & 876 & - & 808 \\
\hline $\begin{array}{c}6 \\
13\end{array}$ & ${ }_{\beta}^{\beta}$ & - & $=$ & $\begin{array}{l}{[(867)]} \\
{[(866)]}\end{array}$ & $\begin{array}{l}[781])] \\
{[803]}\end{array}$ & $\begin{array}{l}(958) \\
(958)\end{array}$ & $\begin{array}{c}(902) \\
917,909\end{array}$ & $\begin{array}{c}(902) \\
898\end{array}$ & $\begin{array}{l}867 \\
(866)\end{array}$ & $\overline{826}$ & $\begin{array}{c}781 \\
803,776\end{array}$ \\
\hline 14 & $\beta$ & {$\left[\begin{array}{c}{[917(909)]} \\
937[917]\end{array}\right.$} & - & $\begin{array}{c}856 \\
-\end{array}$ & [806] & $(975,957)$ & 917 & 898 & - & (845) & 806,773 \\
\hline $8 \mathrm{~A}$ & $\beta$ & (940) & [880] & - & - & 972,965 & 905 & (900) & 880 & - & - \\
\hline 16 & $\beta$ & {$[924,914]$} & - & 861 & - & (978) & $\begin{array}{c}924,914, \\
904\end{array}$ & 893 & - & - & - \\
\hline$\underset{26}{\text { Acyclic }}$ & - & 919 & - & 856 & - & $\begin{array}{c}(975) \\
966\end{array}$ & 919 & 899 & - & - & - \\
\hline $\begin{array}{l}34 \\
35\end{array}$ & $\overline{-}$ & $\begin{array}{l}935 \\
930\end{array}$ & $\begin{array}{c}884,875 \\
877\end{array}$ & $\overline{-}$ & $\begin{array}{c}803,784 \\
803\end{array}$ & $\begin{array}{c}966 \\
(958)\end{array}$ & $\begin{array}{c}928(?) \\
930\end{array}$ & $\begin{array}{l}896 \\
895\end{array}$ & $\begin{array}{c}884,875 \\
877\end{array}$ & $\overline{-}$ & $\begin{array}{l}803,784 \\
803(772)\end{array}$ \\
\hline
\end{tabular}

a See footnotes to table 6 .

pyranose derivatives. Thus, for compounds 13, 14, and 16, some of the $f$ bands of type A could be interpreted as being $p$ bands of type 1. Similarly, for compound $3 \mathrm{~A}$, the type $\mathrm{B}$ and $\mathrm{D}$ bands, and, for compound 6 , the type $C$ and $D$ bands, could be interpreted as being bands of types $2 \mathrm{c}$ and 3 . The three 5-Cmethyl compounds $(6,14$, and 16) show a band in the range of 978 to $957 \mathrm{~cm}^{-1}$, but compounds 13 and $8 \mathrm{~A}$, which lack this grouping, also show a band in this range. The acyclic compounds show $f$ and $p$ bands.
Table 10 lists the bands of five pyranoid compounds having the galacto configuration. All of them show type 2c absorption. None of the unsubstituted compounds show type 3 absorption. The $\alpha$ anomers 7 and 10A show type $2(\alpha)$ absorption, and the $\beta$ anomers do not. The $\alpha$ anomer $10 \mathrm{~A}$ also shows type $2(\beta)$ absorption. All of the $\beta$ anomers show type $2(\beta)$ absorption. All of the pyranoid compounds show some $f$ bands, but some of these bands could equally well be interpreted as being $p$ bands. For example, 
TABLE 10. Bands $\left(\mathrm{cm}^{-1}\right)^{\mathrm{a}}$ in the spectra of compounds having the galacto configuration

\begin{tabular}{|c|c|c|c|c|c|c|c|c|c|c|}
\hline \multirow{4}{*}{ Serial No. } & \multirow{4}{*}{ Anomer } & \multicolumn{4}{|c|}{$f$ bands } & \multicolumn{5}{|c|}{$p$ bands } \\
\hline & & A & B & C & D & 1 & $2(\beta)$ & $2 c(\alpha ; \beta)$ & $2(\alpha)$ & $3(\alpha: \beta)$ \\
\hline & & \multicolumn{9}{|c|}{ Range } \\
\hline & & 937-911 & 886-872 & $865-851$ & $816-782$ & 930-904 & 904-886 & $878-864$ & 836-814 & $772-732$ \\
\hline \multirow[t]{2}{*}{$\begin{array}{c}\text { Pyranoid } \\
7 \\
5 \mathrm{~A}: 8\end{array}$} & $\begin{array}{l}\alpha \\
\beta\end{array}$ & $\begin{array}{c}\text { [930] } \\
-\end{array}$ & $\begin{array}{c}{[873]} \\
-\end{array}$ & {$[(868)]$} & $\begin{array}{l}791 \\
786\end{array}$ & $\begin{array}{l}930 \\
-\end{array}$ & $8 \overline{996}$ & $\begin{array}{l}873 \\
868\end{array}$ & 833 & - \\
\hline & & 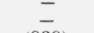 & $=$ & {$[(867)]$} & 786 & $\overline{-}$ & 895 & 867 & $\bar{z}$ & $\begin{array}{l}- \\
-\end{array}$ \\
\hline 15 & $\beta$ & (939) & {$[$ [(888) 876$]$} & 858 & 808.784 & - & \begin{tabular}{|l|}
896,888 \\
\end{tabular} & 876 & - & - \\
\hline $10 \mathrm{~A}$ & $\alpha$ & [921] & - & [862] & - & 921,907 & (907) 899 & (862) & 834 & 757 \\
\hline $11 \mathrm{~A}$ & $\beta$ & [914] & {$[(870)]$} & - & - & 914. 907 & (907) 894 & 870 & - & 734 \\
\hline \multicolumn{11}{|l|}{ Acyclic } \\
\hline 27 & - & - & 879 & (867) 856 & & & & (879) 867 & - & 759 \\
\hline 36 & - & 929 & 875 & - & 803 & 929 & 894 & 875 & - & 745 \\
\hline
\end{tabular}

a See footnotes to table 6 .

for compound 11A, the bands of types A and B could be types 1 and $2 \mathrm{c}$ bands, respectively; the bands for this compound then show complete agreement with the $p$ bands for a $\beta$-galactopyranose. Similarly, for compound $10 \mathrm{~A}$, if the $f$ bands of types $\mathrm{A}$ and $\mathrm{C}$ are actually $p$ bands of types 1 and $2 \mathrm{c}$, the bands agree with those for a galactopyranose, but the presence of types $2(\alpha)$ and $2(\beta)$ bands does not permit a conclusion as to the anomeric configuration. The acyclic compounds listed show $f$ and $p$ bands. The bands for compound 36 correspond with those for a $\beta$-galactopyranose, which shows that use of these bands without other evidence could give an erroneous conclusion.

To be of general usefulness in structural analysis, the correlations made by Barker and co-workers [12] should be applicable to the furanoid and pyranoid forms, respectively, of sugar derivatives of all kinds, provided that allowance is made for bands attributable to such other features as benzene rings or acetate ester groups present in the molecule. However, from the above study, it is apparent that the correlations made by Barker and co-workers [12] are, in most instances, restricted to the compounds they studied, and that the correlations cannot be extended to have a wider diagnostic applicability to related compounds. This conclusion confirms our previous reports that, for cyclic acetals of sugars, "distinctive absorption bands are not apparent for pyranose or furanose rings" [17], and that, for 1-acetamido derivatives of sugars, "no bands were noted which could be correlated with the absence or presence of the pyranoid ring" [2].

\section{Correlations Made by Verstraeten for Fura- noid and Pyranoid Forms of Aldoses and Ketoses}

In 1962, the infrared spectra of most of the readily available aldo- and keto-pentoses and aldo- and keto- hexoses were published [18], but no correlations of bands according to the type-system of Barker and co-workers $[4,5,6,16]$ were given.

However, in 1964, Verstraeten [19] made a study of these spectra, together with those of some additional 2 -ketoses, and obtained evidence that "all of the common sugars having a cyclic structure, and their derivatives, display" absorption at $929 \pm 15 \mathrm{~cm}^{-1}$ (which he designated "type 1"). Exceptions noted were $\alpha$-D-lyxose, showing a band at $965 \mathrm{~cm}^{-1}$, and $\alpha$-Dgalactose, at $960 \mathrm{~cm}^{-1}$. He assigned "type l" absorption to a symmetrical ring-stretching frequency, and apparently regarded his "type 1" absorption as being the same as the type 1 absorption described by Barker and co-workers [4] for glucopyranose derivatives.

Verstraeten found that only furanoses give "type 2" absorption at $850 \pm 6 \mathrm{~cm}^{-1}$ (provided that the ring is free to vibrate). He stated that his type 2 absorption is the same as the type $\mathrm{C}$ absorption of Barker and Stephens [16].

The same author observed that some ketoses, as well as aldoses, show a band at $781 \pm 5 \mathrm{~cm}^{-1}$. $\mathrm{He}$ designated this band "type 3 " and regarded it as being the same as the type 3 absorption mentioned, for several aldoses, by Barker and co-workers $[4,5]$. $\mathrm{He}$ indicated that type 3 absorption was shown provided that two conditions were met: (a) the sugar must have a pyranoid ring, and (b) this pyranoid form must assume a conformation having at least one axial hydroxyl group. He noted that, if the number of axial hydroxyl groups is increased (thereby decreasing the conformational stability), type 3 absorption becomes manifest. For example, $\beta$-(D or L)-xylopyranose-CA, which shows no type 3 absorption, is devoid of axial hydroxyl groups, whereas the $\alpha$ anomer in the CA conformation, which has an axial hydroxyl group at C-1, shows absorption at $760 \mathrm{~cm}^{-1}$. Type 3 absorption was tentatively ascribed to ring-breathing. It was concluded that, if the total structure was suitable, as with compounds having the $\beta$-xylo or $\beta$-ribo configuration in the CA conformation, intramolecular 
TABLE 11. Summary of the results of Verstraeten [19] for infrared bands characteristic of various kinds of sugars and derivatives

\begin{tabular}{|c|c|c|c|c|c|}
\hline \multirow{2}{*}{ Type } & \multicolumn{3}{|c|}{ Aldoses and ketoses } & \multicolumn{2}{|c|}{ Ketoses } \\
\hline & Furanoid & Certain pyranoid a & Furanoid and pyranoid & Furanoid " & Furanoid and pyranoid \\
\hline $\begin{array}{l}1^{\mathrm{c}} \\
2^{\mathrm{d}} \\
33 \\
\mathrm{I}^{\mathrm{e}} \\
\text { IIA }^{\mathrm{r}} \\
\text { IIB }\end{array}$ & $850 \pm \underline{6(856-844)}$ & $781 \pm 5(786-776)$ & $929 \pm 15(944-914)$ & $834 \pm 4(838-830)$ & $\begin{array}{l}874 \pm 9(883-865) \\
817 \pm 7(824-810)\end{array}$ \\
\hline
\end{tabular}

See text.

Substituted, or joined to a pyranoid ring.

c Equated with Barker's type 1 for glucopyranose derivatives $\left(917 \pm 13 \mathrm{~cm}^{-1}\right)$ : Barker and Stephens [16] had pointed out that this is in the same range as their type A for aldo- and keto-furanose derivatives $\left(924 \pm 13 \mathrm{~cm}^{-1}\right)$.

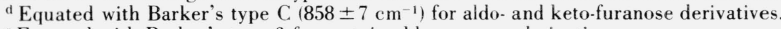

'Equated with Barker's type 3 for certain aldopyranose derivatives.

'In the same range as Barker's type B for aldo- and keto-furanose derivatives $\left(879 \pm 7 \mathrm{~cm}^{-1}\right)$.

${ }^{k}$ In about the same range as Barker's type D for aldo- and keto-furanose derivatives $\left(799 \pm 17 \mathrm{~cm}^{-1}\right)$.

TABLE 12. Types of bands shown by aldoses and ketoses [19]

\begin{tabular}{c|c|c|c}
\hline \multicolumn{3}{c|}{ Aldoses } & \multicolumn{2}{|c}{ Ketoses } \\
\hline Furanose & Pyranose & Furanose & Pyranose \\
\hline 1 & 1 & 1 & 1 \\
2 & - & 2 & - \\
- & -3 & - & I \\
- & - & IIA & IIA \\
- & - & IIB & - \\
\hline
\end{tabular}

a Not shown if the favored conformation has no axial groups

"Shown if the hydroxyl groups of the ketofuranose are substituted (or if $\mathrm{C}-2$ of the keto furanose is joined to a pyranoid or furanoid structure).

linkages (such as van der Waals contact or hydrogen bonds) might be formed, resulting in modification of the ring-breathing, so that absorption at this frequency would not be shown.

Verstraeten also found that 2-ketoses display "type I" bands at $874 \pm 9 \mathrm{~cm}^{-1}$ and "type IIA" bands at $817 \pm 7 \mathrm{~cm}^{-1}$, regardless of whether the sugars are pyranose or furanose. These bands were ascribed to the presence of the following structural feature:

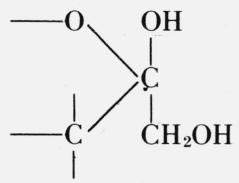

and tentatively assigned to a skeletal vibration. He pointed out that $\alpha$ - and $\beta$-D-lyxose, $\alpha$ - and $\beta$-D-talose, $\alpha$-D-mannose, and $\alpha$-L-fucose (which are not ketoses) also show these bands.

He found that if the ketofuranose ring is substituted, or joined to a pyranoid ring, a type IIB band appears at $834 \pm 4 \mathrm{~cm}^{-1}$, in addition to or instead of the type IIA band. Verstraeten's results are summarized in tables 11 and 12 .

\subsection{Attempted Application of These Correlations to 1-Acylamido Derivatives}

None of the compounds in table 1 are derivatives of ketoses. Hence, we wished to find out (a) whether the spectra of our furanoid compounds showed Verstraeten's $f$-band of type 2 and the band of type 1; and (b) whether the pyranoid compounds showed Verstraeten's $p$-band of type 3 and the band of type 1 . If the bands of types I, IIA, and IIB are usefully diagnostic of ketoses, they should not be shown by the compounds in table 1.

\section{a. Unsubstituted Derivatives}

The bands in the spectra of 13 unsubstituted furanoid and pyranoid 1-acetamido derivatives are listed in table 13. The furanoid compounds 1 and 2 do not show an $f$ band of type 2 , but both show a type 1 band. Both show the ketose band of type I. Compound 1 shows the ketofuranose band of type IIB and the $p$ band of type 3; and compound 2 shows the ketose band of type IIA.

Of the 11 pyranoid compounds, seven do not show the $p$ band of type 3 ; for the five compounds ( $1 \mathrm{~A}, 5 \mathrm{~B}$, $6 \mathrm{~B}, 2 \mathrm{~A}$, and 9) having the $x y l o$, ribo, or gluco configuration, this is in agreement with Verstraeten's correlations. Six do not show the type 1 band. None of them show a type IIA band, so this band may be characteristic of ketoses. Only one of the pyranoid compounds shows a type 2 band, but the two furanoid compounds do not show the band, either. Only two of the eleven pyranoid compounds show a type IIB band, so this band, also, may have some value for diagnosis of ketoses. However, eight of these aldose derivatives show the "type I band of ketoses." Except for the type IIB band shown by compound 7, none of the $\mathrm{N}$-acetylaldohexopyranosylamines show bands of types 2, IIA, and IIB, in agreement with Verstraeten's correlations. The $\beta$-xylopyranose com- 
pound $\mathrm{IA}$ and the $\beta$-glucopyranose compounds (2A and 9) show no bands of types 2, I, IIA, or IIB, in agreement with Verstraeten's correlations.

TABLE 13. Bands $\left(\mathrm{cm}^{-1}\right)$ in the spectra of unsubstituted, furanoid and pyranoid, l-acetamido derivatives

\begin{tabular}{|c|c|c|c|c|c|c|}
\hline \multirow{4}{*}{$\begin{array}{l}\text { Serial } \\
\text { No. }\end{array}$} & \multicolumn{3}{|c|}{ Bands of aldoses (and ketoses) } & \multicolumn{3}{|c|}{ Bands of ketoses } \\
\hline & $1(f, p)$ & $2(f)$ & $3(p)$ & I & IIA & IIB \\
\hline & \multicolumn{6}{|c|}{ Range } \\
\hline & 944-914 & $856-844$ & $786-776$ & $883-865$ & $824-810$ & $838-830$ \\
\hline \multicolumn{7}{|c|}{ Furanoses } \\
\hline & 938 & - & 778 & 883 & - & 831 \\
\hline 2 & 942 & - & - & 867 & 810 & - \\
\hline \multicolumn{7}{|c|}{ Pentopyranoses } \\
\hline $\begin{array}{r}1 \mathrm{~A} \\
5\end{array}$ & $\begin{array}{l}939 \\
-\end{array}$ & $\overline{856}$ & ${ }^{a}-\overline{6}$ & $\overline{8} \overline{8}$ & - & - \\
\hline $4 \mathrm{~A}$ & $936(913)$ & ${ }_{-}^{000}$ & (771) & $(864)$ & $\overline{-}$ & $\bar{z}$ \\
\hline $5 \mathrm{~B}$ & - & - & $b_{-}$ & 882 & - & 838 \\
\hline $6 \mathrm{~B}$ & - & - & b- & 880 & - & - \\
\hline \multicolumn{7}{|c|}{ Hexopyranoses } \\
\hline $\begin{array}{l}2 \mathrm{~A} \\
{\left[9^{\mathrm{d}}\right.}\end{array}$ & $\overline{922}$ & - & ${ }_{-}=$ & $\overline{-}$ & - & $\begin{array}{l}- \\
-1\end{array}$ \\
\hline $3 \mathrm{~A}$ & - & - & - & 876 & - & - \\
\hline 6 & - & - & 781 & 867 & - & - \\
\hline $\begin{array}{c}7 \\
548\end{array}$ & 930 & - & $-\overline{786}$ & 873 & - & 833 \\
\hline $5 \mathrm{~A}, 8$ & 942 & - & 786 & 867 & - & - \\
\hline
\end{tabular}

Table 14 lists the bands in the spectra of six unsubstituted, pyranoid, 1-benzamido derivatives. Only two do not show the $p$ band of type 3 , and for one of these (compound 12), this agrees with Verstraeten's correlations. All of them show the band of type 1 . Four of these pyranoid compounds show the $f$ band of type 2 ; this impairs the diagnostic value of the band. Only one of the compounds shows a type IIA band and only one shows a type IIB band; this strengthens the possibility that these bands have some diagnostic value for ketoses. All but one of the compounds show a "type I band of ketoses," as do ten aldose derivatives listed in table 13; hence, the type I band has no value for diagnosing the presence of the 2 ketose structure.

TABLE 14. Bands $\left(\mathrm{cm}^{-1}\right)$ in the spectra of unsubstituted, pyranoid, 1-benzamido derivatives

\begin{tabular}{|c|c|c|c|c|c|c|}
\hline \multirow{4}{*}{$\begin{array}{c}\text { Serial } \\
\text { No. }\end{array}$} & \multicolumn{3}{|c|}{ Bands of aldoses (and ketoses) } & \multicolumn{3}{|c|}{ Bands of ketoses } \\
\hline & $l(f, p)$ & $2(f)$ & $3(p)$ & I & IIA & IIB \\
\hline & \multicolumn{6}{|c|}{ Range } \\
\hline & 944-914 & $856-844$ & $786-776$ & $883-865$ & $824-810$ & $838-830$ \\
\hline \multicolumn{2}{|c|}{ Pentiopyranoses } & & & & & \\
\hline 10 & 933, 918 & - & - & 870 & - & 830 \\
\hline 11 & 934,928 & 856 & 780 & 880 & & - \\
\hline \multicolumn{2}{|c|}{ Hexopyranoses } & & & & & \\
\hline $\begin{array}{l}12 \\
13\end{array}$ & $\begin{array}{c}917 \\
938.917\end{array}$ & $\overline{856}$ & 376 & 866 & 811 & - \\
\hline 14 & 937,917 & 845 & (773) & - & - & - \\
\hline 15 & 939 & (858) & 784 & 876 & - & - \\
\hline
\end{tabular}

From a study of tables 13 and 14, it may be seen that only two of these aldose derivatives show the type IIA band of ketoses, and only four of them show the type IIB band of ketofuranoses. Of the five compounds showing the type 2 absorption of furanoses, four are 1-benzamido pyranoid derivatives. Also, from a comparison of the spectra of the $\beta$-glycopyranose compounds $2 \mathrm{~A}$ and 12 , it would seem that, for compound 12, the 1-benzamido group must, in some way, be responsible for the bands of types 1 , I, and IIA.

Table 15 lists bands in the spectra of five unsubstituted 1,1-bis(acetamido)-1-deoxyalditols. None of them show the types IIA and IIB bands of ketoses, indicating that these bands may have some diagnostic value. All of these acyclic compounds show the type 1 band of aldoses and ketoses, and all but one show the type I band of ketoses. Two of the five compounds show the type 2 band of furanoses, and two of the five show the type 3 band of certain pyranoid aldoses and ketoses.

\section{TABLE 15. Bands $\left(\mathrm{cm}^{-1}\right)$ in the spectra of unsubstituted} 1,1-bis(acylamido)-1-deoxyalditols

\begin{tabular}{|c|c|c|c|c|c|c|}
\hline \multirow{4}{*}{$\begin{array}{c}\text { Serial } \\
\text { No. }\end{array}$} & \multicolumn{3}{|c|}{ Bands of aldoses (and ketoses) } & \multicolumn{3}{|c|}{ Bands of ketoses } \\
\hline & $1(f, p)$ & $2(f)$ & $3(p)$ & I & IIA & IIB \\
\hline & \multicolumn{6}{|c|}{ Range } \\
\hline & $944-914$ & $856-844$ & $786-776$ & $883-865$ & $824-810$ & $838-830$ \\
\hline \multicolumn{2}{|c|}{ 1,1-Bis(acetamido) } & & & & & \\
\hline 24 & 936 & - & - & 882 & - & - \\
\hline $15 \mathrm{~A}$ & (947) & _ & (775) & 877 & - & - \\
\hline 25 & 930 & - & (787) & 882 & - & - \\
\hline 26 & 919 & 856 & - & - & - & - \\
\hline 27 & 943 & 856 & - & 879,867 & - & - \\
\hline \multicolumn{7}{|c|}{ 1,1-Bis(propionamido) } \\
\hline 28 & 926 & 847 & - & (864) & - & - \\
\hline \multicolumn{7}{|c|}{ 1,1-Bis(benzamido) } \\
\hline 29 & 937,926 & $(843)$ & - & 880 & - & - \\
\hline 30 & 919 & 845 & - & 870 & - & - \\
\hline 31 & 932,916 & - & _- & 881 & - & 838 \\
\hline 32 & 923 & 851 & (775) & 878 & - & - \\
\hline 33 & 930 & 853 & - & 877 & 810 & \\
\hline 34 & 935 & - & 784 & $(884) 875$ & - & $\cdot \quad-$ \\
\hline 35 & 930 & 846 & (772) & 877 & - & - \\
\hline 36 & 929 & 847 & - & 875 & - & - \\
\hline
\end{tabular}

In table 15 are also listed the bands of unsubstituted 1,1-bis(benzamido)-1-deoxyalditols. Only one compound (33) shows type IIA absorption, and only one compound (31) shows type IIB absorption, confirming that these bands have some diagnostic value. However, like the compounds shown in table 14, all of these acyclic compounds show the type 1 band of aldoses and ketoses, and all show the type I band of ketoses. Only two of the eight acyclic compounds do not show the type 2 band of furanoses, and three show the type 3 band of certain pyranoid aldoses and ketoses.

\section{b. Esters}

Verstraeten did not study the infrared spectra of esters. The bands in the spectra of esters of furanoid and pyranoid 1-acetamido derivatives are listed in 
table 16. The furanoid compounds 3 and 4 show the $f$ band of type 2 and the band of type 1, in agreement with Verstraeten's correlations. However, they both show the ketose band of type I. In agreement with Verstraeten's correlations, compound 3 does not show the $p$ band of type 3 ; however, compound 4 shows this band. Compound 3 shows the type IIA band of ketoses, and compound 4 shows the type IIB band of ketoses.

TABLE 16. Bands $\left(\mathrm{cm}^{-1}\right)$ in the spectra of esters of (pyranoid) 1-propionamido and (furanoid and pyranoid) 1-acetamido derivatives

\begin{tabular}{|c|c|c|c|c|c|c|c|}
\hline \multirow{4}{*}{ Serial No. } & \multirow{4}{*}{ Ester } & \multicolumn{3}{|c|}{ Bands of aldoses (and ketoses) } & \multicolumn{3}{|c|}{ Bands of ketoses } \\
\hline & & $1(f, p)$ & $2(f)$ & $3(p)$ & I & IIA & IIB \\
\hline & & \multicolumn{6}{|c|}{ Range } \\
\hline & & $944-914$ & $856-844$ & $786-776$ & $883-865$ & $824-810$ & $838-830$ \\
\hline \multirow{3}{*}{$\begin{array}{l}18 \\
19\end{array}$} & \multirow{3}{*}{$\begin{array}{l}O \cdot \mathrm{Pr} \\
O \cdot \mathrm{Bz}\end{array}$} & \multicolumn{6}{|c|}{ 1-PROPIONAMIDO } \\
\hline & & $\begin{array}{l}934 \\
940\end{array}$ & $-\overline{(858) 847}$ & $a_{-}^{a}$ & $\begin{array}{c}(886,864) \\
-\end{array}$ & $\begin{array}{l}810 \\
-\end{array}$ & $\begin{array}{l}836 \\
830\end{array}$ \\
\hline & & \multicolumn{6}{|c|}{ 1-ACETAMIDO } \\
\hline \multicolumn{2}{|c|}{$\underset{3}{\text { Furanoses }}, \mathrm{O} \cdot \mathrm{Bz}$} & & & & & & \\
\hline $\begin{array}{l}3 \\
4\end{array}$ & $\begin{array}{l}O \cdot \mathrm{Bz} \\
O \cdot \mathrm{Bz}\end{array}$ & $\begin{array}{l}943 \\
939\end{array}$ & $\begin{array}{l}(860) \\
(857)\end{array}$ & $\overline{776}$ & $\begin{array}{c}(887) 871 \\
(885)\end{array}$ & $\begin{array}{c}824,810 \\
-\end{array}$ & 830 \\
\hline \multicolumn{2}{|c|}{ Pentopyranoses } & & & & & & \\
\hline 17 & $O \cdot \mathrm{Bz}$ & 944,935 & 851 & 774 & (862) & - & (828) \\
\hline $6 \mathrm{~A}$ & $O$-Ac & 934 & - & ${ }^{3}-$ & 877 & - & - \\
\hline $9 \mathrm{~A}$ & $O$-Ac & 944,933 & - & - & 870 & - & - \\
\hline $4 \mathrm{~B}$ & $O \cdot A \mathrm{c}$ & 936 & - & ${ }^{c}-$ & 870 & - & - \\
\hline \multicolumn{2}{|c|}{ Hexopyranoses } & & & & & & \\
\hline & $O-A c$ & 917 & - & ${ }^{a}$ & 871 & - & - \\
\hline $8 \mathrm{~A}$ & $O-A c$ & 940 & - & - & 880 & - & - \\
\hline 16 & $O$-Ac & $\begin{array}{c}(945) \\
924,914\end{array}$ & - & - & (861) & - & - \\
\hline $10 \mathrm{~A}$ & $O-A c$ & 943,921 & - & - & (862) & - & 834 \\
\hline $11 \mathrm{~A}$ & $O$-Ac & 914 & - & - & 870 & - & - \\
\hline
\end{tabular}

${ }^{\mathrm{a}}$ gluco. ${ }^{\mathrm{b}}$ xylo. ${ }^{\mathrm{c}}$ ribo.

Of the eight pyranoid acetates, none show the $f$ band of type 2, and all show the band of type 1 , in agreement with Verstraeten's correlations. However, none of them show the type 3 band, although only three (compounds $6 \mathrm{~A}, 4 \mathrm{~B}$, and $7 \mathrm{~A}$ ) would be expected not to show it. In agreement with Verstraeten's correlations, none of them show the type IIA band, and all but one (compound 10A) do not show the type IIB band. However, all of them show the type I band of ketoses.

The pyranoid benzoates (compounds 17 and 19) show the band of type 1 and do not show the type IIA band, in agreement with Verstraeten's correlations. However, they both show the $f$ band of type 2 and the ketose band of type IIB. Compound 17 shows the $p$ band of type 3, but compound 19 does not, in agreement with Verstraeten's correlations. Like the acetates in table 16, the propionate (18) and the benzoate (17) show the type I absorption of ketoses, but benzoate 19 does not. The 1-propionamido compounds (18 and 19) show absorption of type 1 but not type 3 absorption, in-agreement with Verstraeten's correlations; however, they both show the type IIB absorption of ketofuranoses. Of the pyranoid compounds in table 16, compounds $6 \mathrm{~A}, 4 \mathrm{~B}, 7 \mathrm{~A}, 18$, and 19 would be expected not to show type 3 absorption and they do not, in agreement with Verstraeten's correlations. However, compounds 9A, 17, 8A, 10A, and $11 \mathrm{~A}$ would be expected to show type 3 absorption, but only compound 17 shows it.

Table 17 lists the bands of esters of pyranoid 1-benzamido derivatives. All of them show the type 1 band, in agreement with Verstraeten's correlations. However, they all show the $f$ band of type 2 and the type I band of ketoses. Compounds 21, 23, and 23a do not show the $p$ band of type 3 , whereas compound 22 does, in agreement with Verstraeten's correlations. However, compound 20 does not show this band. Three of the five compounds show the type IIA band of ketoses, and two show the type IIB band of ketofuranoses.

TABLE 17. Bands $\left(\mathrm{cm}^{-1}\right)$ in the spectra of esters of pyranoid, l-benzamido derivatives

\begin{tabular}{|c|c|c|c|c|c|c|}
\hline \multirow{4}{*}{$\begin{array}{l}\text { Serial } \\
\text { No. }\end{array}$} & \multicolumn{3}{|c|}{ Bands of aldoses (and ketoses) } & \multicolumn{3}{|c|}{ Bands of ketoses } \\
\hline & $l(f, p)$ & $2(f)$ & $3(p)$ & I & IIA & IIB \\
\hline & \multicolumn{6}{|c|}{ Range } \\
\hline & $944-914$ & $856-844$ & $786-776$ & $883-865$ & $824-810$ & $838-830$ \\
\hline $\begin{array}{c}\boldsymbol{O} \text {-Acetyl } \\
20\end{array}$ & $\begin{array}{c}(947) 931 \\
917\end{array}$ & 851 & - & 876 & $(808)$ & - \\
\hline $\begin{array}{c}\text { O-Benzo } \\
21 \\
22 \\
23 \\
23 a\end{array}$ & $\begin{array}{c}\text { I } \\
939(913) \\
(945) 937 \\
940 \\
940,922\end{array}$ & $\begin{array}{c}853 \\
851 \\
(858) 845 \\
855\end{array}$ & $\begin{array}{c}\mathrm{a}_{-} \\
(772) \\
\mathrm{b}- \\
\mathrm{b}-\end{array}$ & $\begin{array}{l}870 \\
877 \\
870 \\
874\end{array}$ & $\begin{array}{c}824 \\
824 \\
- \\
-\end{array}$ & $\begin{array}{l}- \\
\overline{831} \\
830\end{array}$ \\
\hline
\end{tabular}

a $x y l o .{ }^{\mathrm{b}}$ gluco.

In table 18 are listed the bands of nine esters of 1,1-bis(acylamido)-1-deoxyalditols. All of these acyclic compounds show types 1 and I bands. All of the acetates, but none of the benzoates or acetate-benzoates, show a band of type 3 . All of the benzamido compounds show a band of type IIA. Only two of the compounds do not show an $f$ band of type 2 . Three of the compounds show the type IIB band of ketofuranoses, and they possess both $O$-benzoyl and 1,1-bis(benzamido) groups.

\section{c. Summation}

The results are summarized in table 19, which lists, by the categories in tables 13 to 18 , the compounds in this study that fit Verstraeten's correlations. For this purpose, an agreement score of unity is given if the spectrum of a compound (a) shows a predicted band or (b) does not show a band predicted to be absent; a score of zero is given if the spectrum (a) does not show a predicted band or (b) shows a band 
TABLE 18. Bands $\left(\mathrm{cm}^{-1}\right)$ in the spectra of esters of 1,1-bis(acylamido)1-deoxyalditols

\begin{tabular}{|c|c|c|c|c|c|c|}
\hline \multirow{4}{*}{$\begin{array}{l}\text { Serial } \\
\text { No. }\end{array}$} & \multicolumn{3}{|c|}{ Bands of aldoses (and ketoses) } & \multicolumn{3}{|c|}{ Bands of ketoses } \\
\hline & $1(f, p)$ & $2(f)$ & $3(p)$ & I & IIA & IIB \\
\hline & \multicolumn{6}{|c|}{ Range } \\
\hline & $944-914$ & $856-844$ & $786-776$ & $883-865$ & $824-810$ & $838-830$ \\
\hline & \multicolumn{6}{|c|}{ ACETATES } \\
\hline \multicolumn{7}{|c|}{ Acetamido } \\
\hline $16 \mathrm{~A}$ & 929.921 & 855 & 784 & 871 & - & - \\
\hline 37 & $\begin{array}{c}937,925 \\
917\end{array}$ & 850 & 778(?) & (862) & - & - \\
\hline \multicolumn{7}{|c|}{ Benzamido } \\
\hline 42 & 941.935 & 847 & 778(?) & 879 & & - \\
\hline 43 & 935 & 847 & (775) & 870 & $820(?)$ & - \\
\hline 44 & 935.917 & - & (772) & 868 & 824 & - \\
\hline \multicolumn{7}{|c|}{ BENZOATES } \\
\hline \multicolumn{7}{|c|}{ Benzamido } \\
\hline \multirow{3}{*}{$\begin{array}{l}38 \\
41\end{array}$} & 940,929 & 849 & - & 870 & 810 & - \\
\hline & $\begin{array}{l}\text { 938, 933, } \\
\text { (911) }\end{array}$ & 851,846 & - & 867 & 822 & $(840)$ \\
\hline & \multicolumn{6}{|c|}{ ACETATE-BENZOATES } \\
\hline $\begin{array}{l}39 \\
40\end{array}$ & $\begin{array}{c}926,917 \\
939,932, \\
921\end{array}$ & 855 & - & $\begin{array}{l}871 \\
873\end{array}$ & $\begin{array}{c}(809) \\
(808)\end{array}$ & $\begin{array}{l}837 \\
(829)\end{array}$ \\
\hline
\end{tabular}

TABLE 19. Number of compounds of each category that fit Verstraeten's correlations

\begin{tabular}{|c|c|c|c|c|c|c|c|c|}
\hline \multicolumn{3}{|c|}{ Compounds studied } & \multicolumn{6}{|c|}{ No. of compounds fitting band of type } \\
\hline $\begin{array}{c}\text { In table } \\
\text { No. }\end{array}$ & $\begin{array}{c}\text { Structural } \\
\text { type }\end{array}$ & No. & 1 & 2 & 3 & I & IIA & IIB \\
\hline \multirow{3}{*}{$\underset{13}{\text { Furanose }}$} & & & & & & & & \\
\hline & $\begin{array}{l}N-\mathrm{Ac} \\
N \cdot \mathrm{Ac}, O \cdot \mathrm{Bz}\end{array}$ & $\begin{array}{l}2 \\
2\end{array}$ & $\begin{array}{l}2 \\
2\end{array}$ & $\begin{array}{l}0 \\
2\end{array}$ & $\begin{array}{l}1 \\
1\end{array}$ & $\begin{array}{l}0 \\
0\end{array}$ & 1 & $\begin{array}{l}1 \\
1\end{array}$ \\
\hline & \multicolumn{2}{|l|}{ Total } & 4 & 2 & 2 & 0 & 2 & 2 \\
\hline \multicolumn{2}{|c|}{ Pyranoses } & & & & & & & \\
\hline 13 & $N$-Ac & 10 & 4 & 9 & 8 & 2 & 10 & 8 \\
\hline 14 & & $\begin{array}{l}1 \\
6\end{array}$ & $\begin{array}{l}1 \\
6\end{array}$ & $\frac{1}{2}$ & $\frac{1}{5}$ & 1 & $\frac{1}{5}$ & $\frac{1}{5}$ \\
\hline \multirow[t]{3}{*}{16} & $N$-Ac. $O$-Ac & 8 & 8 & 8 & 3 & 0 & 8 & 7 \\
\hline & $N$-Pr. O-Pr & 1 & 1 & 1 & 1 & 0 & 0 & 0 \\
\hline & $\begin{array}{l}N \text {-Ac, } O \text {-Bz } \\
N \operatorname{Pr}, O B z\end{array}$ & $\begin{array}{l}1 \\
1\end{array}$ & 1 & 0 & 1 & $\begin{array}{l}0 \\
1\end{array}$ & 1 & $\begin{array}{l}0 \\
0\end{array}$ \\
\hline \multirow[t]{3}{*}{17} & $N$-Bz. $O$-Ac & l & 1 & 0 & 0 & 0 & 0 & 1 \\
\hline & $N$-Bz. $O \cdot$ Bz & 4 & 4 & 0 & 4 & 0 & 2 & 2 \\
\hline & \multicolumn{2}{|l|}{ Total } & 27 & 21 & 24 & 5 & 28 & 24 \\
\hline \multirow{4}{*}{$\begin{array}{c}\text { Acyclic } \\
15\end{array}$} & & & & & & & & \\
\hline & $N \cdot A \mathrm{c}$ & 5 & 0 & 3 & 3 & 1 & & 5 \\
\hline & & $\begin{array}{l}1 \\
8\end{array}$ & $\begin{array}{l}0 \\
0\end{array}$ & 0 & $\frac{1}{5}$ & $\begin{array}{l}0 \\
0\end{array}$ & $\frac{1}{7}$ & $\frac{1}{7}$ \\
\hline & & $\begin{array}{l}8 \\
2\end{array}$ & $\begin{array}{l}0 \\
0\end{array}$ & ${ }_{0}^{2}$ & $\begin{array}{l}5 \\
0\end{array}$ & $\begin{array}{l}0 \\
0\end{array}$ & 7 & $?$ \\
\hline \multirow{5}{*}{18} & $\begin{array}{l}\text { N.Ac. } O \text {-Ac } \\
\text { N-Bz. } O \text {-Ac }\end{array}$ & 3 & 0 & 1 & 0 & 0 & 0 & 3 \\
\hline & $N \cdot \mathrm{Bz} . O \cdot \mathrm{Bz}$ & 2 & 0 & 0 & 2 & 0 & 0 & 1 \\
\hline & $\begin{array}{c}N-\mathrm{Bz}, O-\mathrm{Ac}, \\
O-\mathrm{Bz}\end{array}$ & 2 & 0 & 1 & 2 & & 0 & \\
\hline & Total & 23 & 0 & 7 & 13 & 1 & 15 & 19 \\
\hline & Grand total & 60 & 31 & 30 & 39 & 6 & 45 & 45 \\
\hline
\end{tabular}

predicted to be absent. From these results, an estimate of diagnostic value (see table 20) of each type of band was made, on the assumption that an agreement of 50 percent or less has no diagnostic value, but an agreement near 100 percent has diagnostic value. An agreement lying between 50 and 100 percent may have some value as being indicative of a possibility that must be further explored. Table 21 lists the results for six separate compounds, for comparison.

Verstraeten [19] pointed out that the type 1 band is shown by the cyclic aldoses and ketoses that he studied; as may be seen from tables 20 and 21 , this is now confirmed, except for some of the 1-acetamido pyranoses (see table 13). Consequently, to have diagnostic value, the band should not be shown by the acyclic derivatives: however, the type 1 band is shown by them (see tables 15 and 18). As may be seen from tables 20 and 21 , the type 1 band has no diagnostic value for the acyclic derivatives. Hence, it has no diagnostic value at all in distinguishing between cyclic and acyclic structures for the compounds in this study.

TABLE 20. Diagnostic value of Verstraeten's correlations for the various categories of compounds

\begin{tabular}{|c|c|c|c|c|c|c|c|c|}
\hline \multicolumn{3}{|c|}{ Compounds studied } & \multicolumn{6}{|c|}{ Diagnostic value a of band of type } \\
\hline $\begin{array}{c}\text { In table } \\
\text { No. }\end{array}$ & $\begin{array}{c}\text { Structural } \\
\text { type }\end{array}$ & No. & 1 & 2 & 3 & I & IIA & IIB \\
\hline \multicolumn{9}{|c|}{ Aldofuranoses } \\
\hline 13 & & 2 & {$[++]$} & 0 & 0 & 0 & 0 & 0 \\
\hline 16 & $N$-Ac. $O$-Bz & 2 & {$[++]$} & ++ & 0 & 0 & 0 & 0 \\
\hline \multicolumn{9}{|c|}{ Aldopyranoses } \\
\hline 13 & $N$-Ac & 10 & {$[0]$} & + & + & 0 & ++ & + \\
\hline 14 & $N-\mathrm{Bz}_{2}$ & 6 & {$[++]$} & 0 & + & 0 & + & + \\
\hline 16 & $N$-Ac. $O$-Ac & 8 & {$[++]$} & ++ & 0 & 0 & ++ & + \\
\hline 17 & $N$-Bz. $O$-Bz & 4 & {$[++]$} & 0 & ++ & 0 & 0 & 0 \\
\hline \multicolumn{9}{|l|}{ Acyclic } \\
\hline 15 & $N-\mathrm{A}$ & 5 & & $+?$ & + ? & 0 & ++ & ++ \\
\hline \multirow{4}{*}{18} & & 8 & 0 & 0 & $+?$ & 0 & + & + \\
\hline & $N$-Ac, O-Ac & 2 & 0 & 0 & 0 & 0 & ++ & ++ \\
\hline & $N$-Bz. $O$-Ac & 3 & $\begin{array}{l}0 \\
0\end{array}$ & 0 & $\begin{array}{c}0 \\
++\end{array}$ & $\begin{array}{l}0 \\
0\end{array}$ & $\begin{array}{l}0 \\
0\end{array}$ & $\begin{array}{c}++ \\
0\end{array}$ \\
\hline & $\begin{array}{l}N \text {-Bz. } O \text {-Bz } \\
N \text {-Bz. } O \text {-Ac. }\end{array}$ & $\frac{2}{2}$ & $\begin{array}{l}0 \\
0\end{array}$ & $\begin{array}{l}0 \\
0\end{array}$ & $\begin{array}{l}++ \\
++ \\
++\end{array}$ & 0 & 0 & 0 \\
\hline
\end{tabular}

a Key:,$++ 100 \%$ agreement: + , nearly $100 \%$ agreement: + ? above $50 \%$. but much less than $100 \%$ agreement: 0 . agreement of $50 \%$ or less.

TABLE 21. Diagnostic value of Verstraeten's correlations applied to single compounds of various categories

\begin{tabular}{|c|c|c|c|c|c|c|c|c|}
\hline \multicolumn{3}{|c|}{ Compounds studied } & \multicolumn{6}{|c|}{ Diagnostic value a of band of type } \\
\hline $\begin{array}{c}\text { In table } \\
\text { No. }\end{array}$ & $\begin{array}{c}\text { Serial } \\
\text { No. }\end{array}$ & $\begin{array}{c}\text { Structural } \\
\text { type }\end{array}$ & 1 & 2 & 3 & I & IIA & IIB \\
\hline \multicolumn{2}{|c|}{ Pyranoses } & & & & & & & \\
\hline \multirow{4}{*}{$\begin{array}{l}13 \\
16\end{array}$} & 9 & $N \cdot \operatorname{Pr}$ & [+] & + & + & + & + & + \\
\hline & 18 & N.Pr, O-Pr & {$[+]$} & + & + & & 0 & \\
\hline & 19 & $N \cdot \operatorname{Pr}, O-\mathrm{Bz}$ & {$[+]$} & 0 & + & + & + & 0 \\
\hline & 17 & $N$ Ac, $O \cdot \mathrm{Bz}$ & {$[+]$} & 0 & + & 0 & + & 0 \\
\hline 17 & 20 & $N \cdot \mathrm{Bz}, O \cdot \mathrm{Ac}$ & {$[+]$} & 0 & 0 & 0 & 0 & + \\
\hline \multirow[t]{2}{*}{ Aeyclic } & & & & & & & & \\
\hline & 28 & $N \cdot \operatorname{Pr}$ & 0 & 0 & + & 0 & + & + \\
\hline
\end{tabular}

${ }^{a}$ Key: + , agrees with correlation: 0 , does not agree with correlation. 
From line 1 of table 20, it may be seen that none of the bands (including type 1 , for the reasons just given) have diagnostic value for the two aldofuranoses studied (table 13); but, on benzoylation (table 16), the $f$ band of type 2 becomes manifest. Similarly, the diagnostic value of the type 2 band for the 1-acetamido pyranoses (table 13) is increased by acetylation (table 16); but the band has no diagnostic value for the 1-benzamido pyranoses (table 14), and benzoylation (table 17) has no effect on the value. The type 2 band has no diagnostic value for distinguishing furanoses from the acyclic compounds (tables 15 and 18).

Except for the furanoses (tables 13 and 16), the type 3 band has diagnostic value for all of the benzoates (tables 16,17, and 18), but not for the acetates (tables 16, 17, and 18); it may have value for the unesterified compounds (tables 13, 14, and 15).

From table 20, it may be seen that the band of type $I$ has no diagnostic value for any of the compounds; for this band, the results in table 21 have no statistical significance.

Except for the furanoses (tables 13 and 16) and the esters of 1-benzamido compounds (tables 17 and 18), the type IIA band has excellent diagnostic value. The same is true for the type IIB band, which also has diagnostic value for the acetylated 1,1-bis(acetamido) alditols.

Consequently, for the compounds discussed in this study, the bands of types 1 and I have no diagnostic value. Secondly, before a spectrum is checked for the presence or absence of bands of types 2,3 , IIA, and IIB, it should be examined for the presence or absence of the group frequencies characteristic of the $O$-acetyl and $O$-benzoyl groups. If no ester group is present, the spectrum should be examined for the group frequencies characteristic of the $N$-acetyl and $N$-benzoyl groups. (a) If the $N$-acetyl group is present, the Verstraeten bands have no diagnostic value for the furanoid compounds 1 and 2 . If these structures are eliminated from consideration by the results of some other kind of test, the bands of types 2, 3, IA, and IIA may have diagnostic value. (b) Should the $N$-benzoyl group be present, the type 2 band has no diagnostic value, but the bands of types 3 , IA, and IIA should be useful.

If an ester group is present, it may be seen (from table 20) that, for the $N$-acetyl- $O$-acetyl compounds, the bands of types IIA and IIB differentiate between Verstraeten's ketoses and our nonketoses, but cyclic compounds cannot be distinguished from acyclic compounds. Insufficient evidence is available for the $N$-acetyl- $O$-benzoyl compounds; compounds 3 and 4 show the $f$ band of type 2 , but this band has no diagnostic value for compound 17 . As regards the $N$ benzoyl- $O$-acetyl compounds, only the type IIB band has diagnostic value. For the $N$-benzoyl- $O$-benzoyl compounds, only the type 3 band has diagnostic value.

\section{Correlations Made by Nanasi and Co-workers}

Nanasi and co-workers [20] have made some correlations for infrared spectra of $N$ - $p$-tolyl- $\alpha$-and- $\beta$-D- glucopyranosylamines and their tetraacetates, and for tetramethyl ethers of the $N$-p-tolylglycosylamines having the $\alpha$-D-glucofuranosyl, $\alpha$-D-glucopyranosyl, and $\beta$-D-galactopyranosyl structures. They also made correlations for the $N$ - $p$-bromophenylglycosylamines having the 2 -deoxy- $\beta$-D-arabino-hexopyranosyl, $\beta$-Dglucopyranosyl, and $\beta$-D-galactopyranosyl structures, and for the tetraacetates of the last two. In the range of wavelengths we have discussed, most of their correlations agreed with those of Barker and co-workers [12], and so, detailed comment is not necessary. We have found that their correlations cannot be extended to the compounds described in the present article.

\section{Other Absorption Bands}

All of the compounds in this study are secondary amides, and all of them show at least one band at 3460 to $3226 \mathrm{~cm}^{-1}$ (N-H stretching); in this region, the completely esterified compounds (group la, table 22) could not be distinguished from those having free hydroxyl groups (group lb) that would show O-H stretching in the same region. All of the compounds show a band at $1681-1626 \mathrm{~cm}^{-1}$ (amide I) and at 1575 to $1504 \mathrm{~cm}^{-1}$ (amide II). The bis(acylamido) compounds (group ld) show two amide II bands, suggesting that the two acylamido groups on C-1 of these compounds are not equivalent. They may have a hydrogen-bonded structure, possibly of the following type.

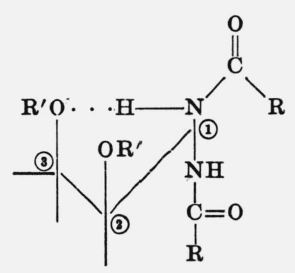

where $\mathrm{R}$ is $\mathrm{Me}, \mathrm{Et}$, or $\mathrm{Ph}$; and $\mathrm{R}^{\prime}$ is $\mathrm{H}, \mathrm{Ac}, \mathrm{EtCO}$, or $\mathrm{Bz}$.

TABLE 22. Structural groups studied

\begin{tabular}{|c|c|c|}
\hline Group & Structural feature & $\begin{array}{l}\text { Compounds (serial numbers) } \\
\text { in group }\end{array}$ \\
\hline $\begin{array}{l}\text { l } \\
\text { a } \\
\text { b } \\
\text { c } \\
\text { d }\end{array}$ & $\begin{array}{l}\text { Amide, secondary } \\
\text { no hydroxyl group } \\
\text { free hydroxyl groups } \\
\text { mono(acylamido) } \\
\text { bis(acylamido) }\end{array}$ & $\begin{array}{l}3,4,16-23 \mathrm{a}, 37,39-44,6 \mathrm{~A}-11 \mathrm{~A}, \\
16 \mathrm{~A}, 4 \mathrm{~B} \\
1,2,5-15,24-36,38,1 \mathrm{~A}-5 \mathrm{~A}, 15 \mathrm{~A}, \\
5 \mathrm{~B}, 6 \mathrm{~B} \\
1-23 \mathrm{a}, 1 \mathrm{~A}-11 \mathrm{~A}, 4 \mathrm{~B}-6 \mathrm{~B} \\
24-44,15 \mathrm{~A}, 16 \mathrm{~A}\end{array}$ \\
\hline $\begin{array}{l}2 \\
\text { a } \\
\text { b } \\
\text { c } \\
\text { d }\end{array}$ & $\begin{array}{l}\text { Esters } \\
\text { acetates } \\
\text { propionate } \\
\text { benzoates } \\
\text { mixed acetate-benzoates }\end{array}$ & $\begin{array}{l}16,20,37,42-44,6 \mathrm{~A}-11 \mathrm{~A}, 16 \mathrm{~A}, 4 \mathrm{~B} \\
18 \\
3,4,17,19,21-23 \mathrm{a}, 38,41 \\
39,40\end{array}$ \\
\hline $\begin{array}{l}3 \\
\mathbf{a} \\
\mathrm{b}\end{array}$ & $\begin{array}{l}\text { Phenyl group } \\
N \text {-benzoyl, } O \text {-benzoyl, or both } \\
\text { no phenyl group }\end{array}$ & $\begin{array}{l}3,4,10-15,17,19-23 \mathrm{a}, 29-36, \\
38-44 \\
1,2,5-9,16,18,24-28,37,1 \mathrm{~A}-11 \mathrm{~A}, \\
15 \mathrm{~A}, 16 \mathrm{~A}, 4 \mathrm{~B}-6 \mathrm{~B}\end{array}$ \\
\hline
\end{tabular}


All of the compounds show a band at 1311 to 1258 $\mathrm{cm}^{-1}$ ("amide III"). All of the acyclic compounds having a benzoyl group show the amide $\mathrm{V}$ band at 712 to $689 \mathrm{~cm}^{-1}$, and this band is shown by many of the other compounds in this study.

The acetates and the tetrapropionate (groups 2a and $2 \mathrm{~b})$ show a band at 1761 to $1742 \mathrm{~cm}^{-1}(\mathrm{C}=\mathrm{O}$ stretching), except for compound $4 \mathrm{~B}$, which shows a band at $1718 \mathrm{~cm}^{-1}$. The benzoates (group 2c) show a band at 1745 to $1727 \mathrm{~cm}^{-1}$, except for the monobenzoate (compound 38) which shows a band at $1698 \mathrm{~cm}^{-1}$. The mixed esters (group 2d) show two bands in this region: compound 39 at 1742 and $1715 \mathrm{~cm}^{-1}$, and compound 40 at 1761 and $1745 \mathrm{~cm}^{-1}$.

All of the compounds containing a phenyl group (group 3a) show bands at 1613 to $1600 \mathrm{~cm}^{-1}, 1587$ to $1567 \mathrm{~cm}^{-1}$, and 1506 to $1477 \mathrm{~cm}^{-1}$. All of the compounds containing a phenyl group also show a band at 811 to $798 \mathrm{~cm}^{-1}$; a band ( $f$ band of type D) in this region is also shown by the furanoid compounds 1 and 2 , which lack a phenyl group. Consequently, this band has no diagnostic value for the furanoid ring if benzoyl groups are present. The propionate (compound 18) shows a band at $810 \mathrm{~cm}^{-1}$, and the bis(propionamido) compound 28 shows a band at $807 \mathrm{~cm}^{-1}$, but the propionamido compound 9 shows no band in this region. Compounds 38, 39, and 40, which are 1,1 bis(benzamido) compounds having a lone, terminal, $O$-benzoyl group, show two distinct bands in this region (810 to $\left.798 \mathrm{~cm}^{-1}\right)$.

\section{Experimental Procedures}

\subsection{Preparation and Purification of the Compounds}

The compounds listed in table 1 were prepared by the methods given in the references cited. Each compound was recrystallized from an appropriate solvent until further recrystallization caused no change in melting point or optical rotation.

\subsection{Measurement of Infrared Absorption}

The spectrograms were recorded with a PerkinElmer Model 137 spectrophotometer ${ }^{4}$ which was calibrated against a polystyrene standard (found value and deviation in parentheses): $3030(3096 ;+66), 2924$ $(2976 ;+52), 2849(2865 ;+16), 1946(1953 ;+7), 1802$ (1808 to $1805 ;+6$ to +3 ), 1603 (1605 to $1600 ;+2$ to $-3), 1495$ (1495 to $1493 ; 0$ to -2$), 1155$ (1155 to 1153 ; 0 to -2$), 1029$ (1029 to $1028 ; 0$ to -1$)$, and 906 (907; $+1) \mathrm{cm}^{-1}$, and against polyethylene: 720 (720 to 719; 0 to -1$) \mathrm{cm}^{-1}$.

The spectrograms (see fig. 1) were recorded for Nujol mulls of the samples, and the bands of Nujol were used as an internal reference standard. In this study, the bands in the range of 4000 to $1800 \mathrm{~cm}^{-1}$ were of little interest, and the bands observed were corrected by reference to the above calibration and to the Nujol band at $2861 \mathrm{~cm}^{-1}$. For bands in the range of 1800 to $667 \mathrm{~cm}^{-1}$, the observed bands were not corrected. As, in some instances, the bands of interest occurred inside a range of as much as $26 \mathrm{~cm}^{-1}$, and as (in the range of 1000 to $730 \mathrm{~cm}^{-1}$ ) this instrument gave results to $\pm 2 \mathrm{~cm}^{-1}$, the instrument was considered to be sufficiently accurate for our purposes. For example, for compound $15 \mathrm{~A}$, the bands in the region of 1000 to $730 \mathrm{~cm}^{-1}$ were compared with those recorded for the same specimen with a Beckman Model IR4 (double beam) spectrophotometer ${ }^{4}$ (latter results in parentheses) as follows: 966 (964), 948 (947), 906 (904), $879(877)$, 775 (775), 741 (742), and $714(714) \mathrm{cm}^{-1}$. For compound $5 \mathrm{~A}$, the bands were compared with those obtained with a Perkin-Elmer Model 21 (double beam) spectrophotometer ${ }^{4}$ (latter results in parentheses): ca. 995 (ca. 995), 968 (967), 948 (947), 943 (942), 896 (895), $868(867)$, and $786(786) \mathrm{cm}^{-1}$.

${ }^{4}$ Certain commercial instruments are identified in this paper in order to specify adequately the experimental procedure. In no case does such identification imply recom. mendation or endorsement by the National Bureau of Standards, nor does it imply that the equipment identified is necessarily the best available for the purpose. 


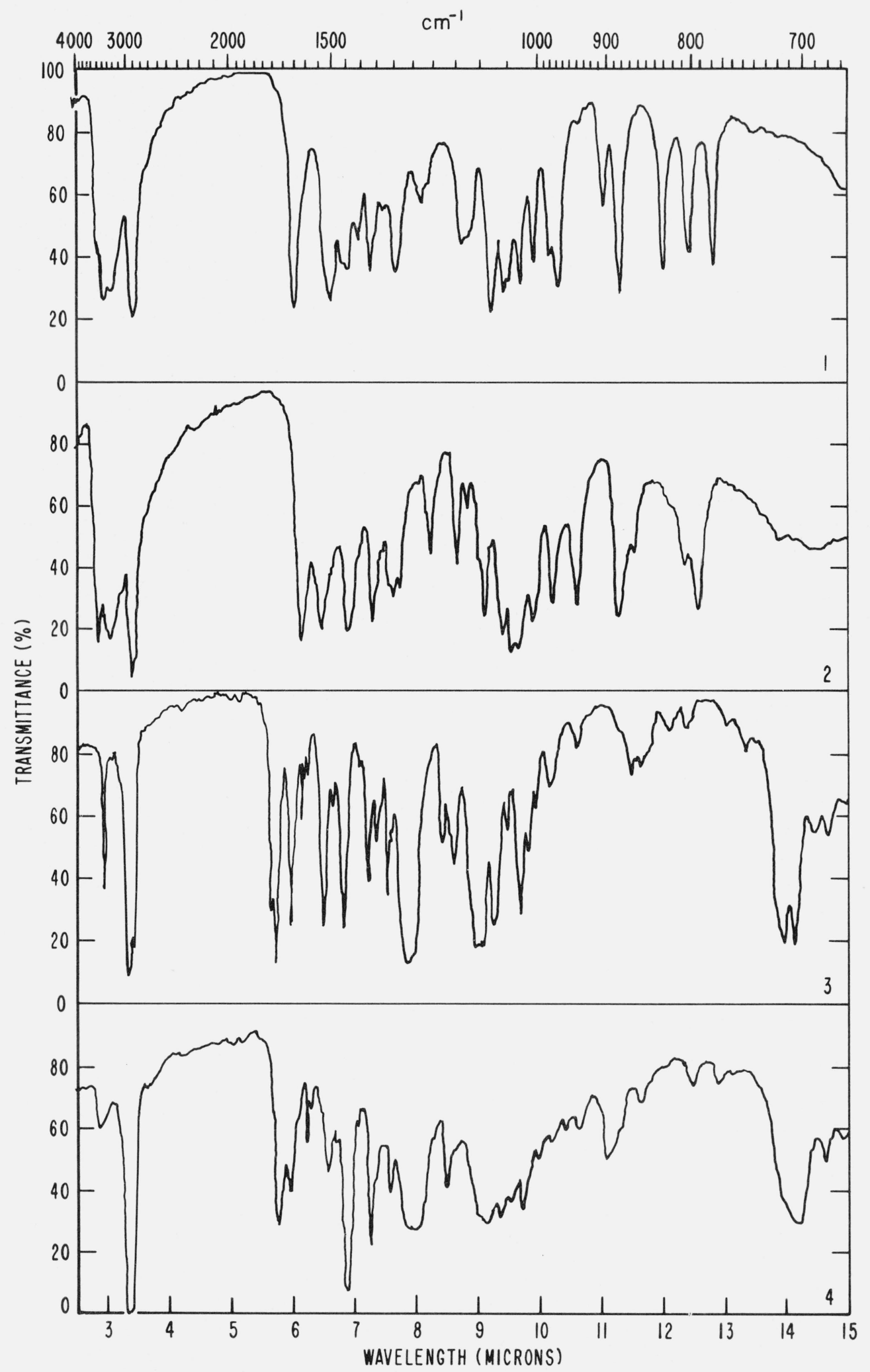

FIGURE 1. Spectrograms of compounds in Nujol mulls.

1, $N$-Acetyl- $\alpha$-D-xylofuranosylamine; $2, N$-acetyl- $\alpha$-D-glucofuranosylamine; 3, $N$-acetyl-2,3,5-tri- $O$-benzoyl- $\alpha$-D-xylofuranosylamine;

4, $N$-acetyl-2,3,5,6-tetra- $O$-benzoyl- $\alpha$-D-glucofuranosylamine. 


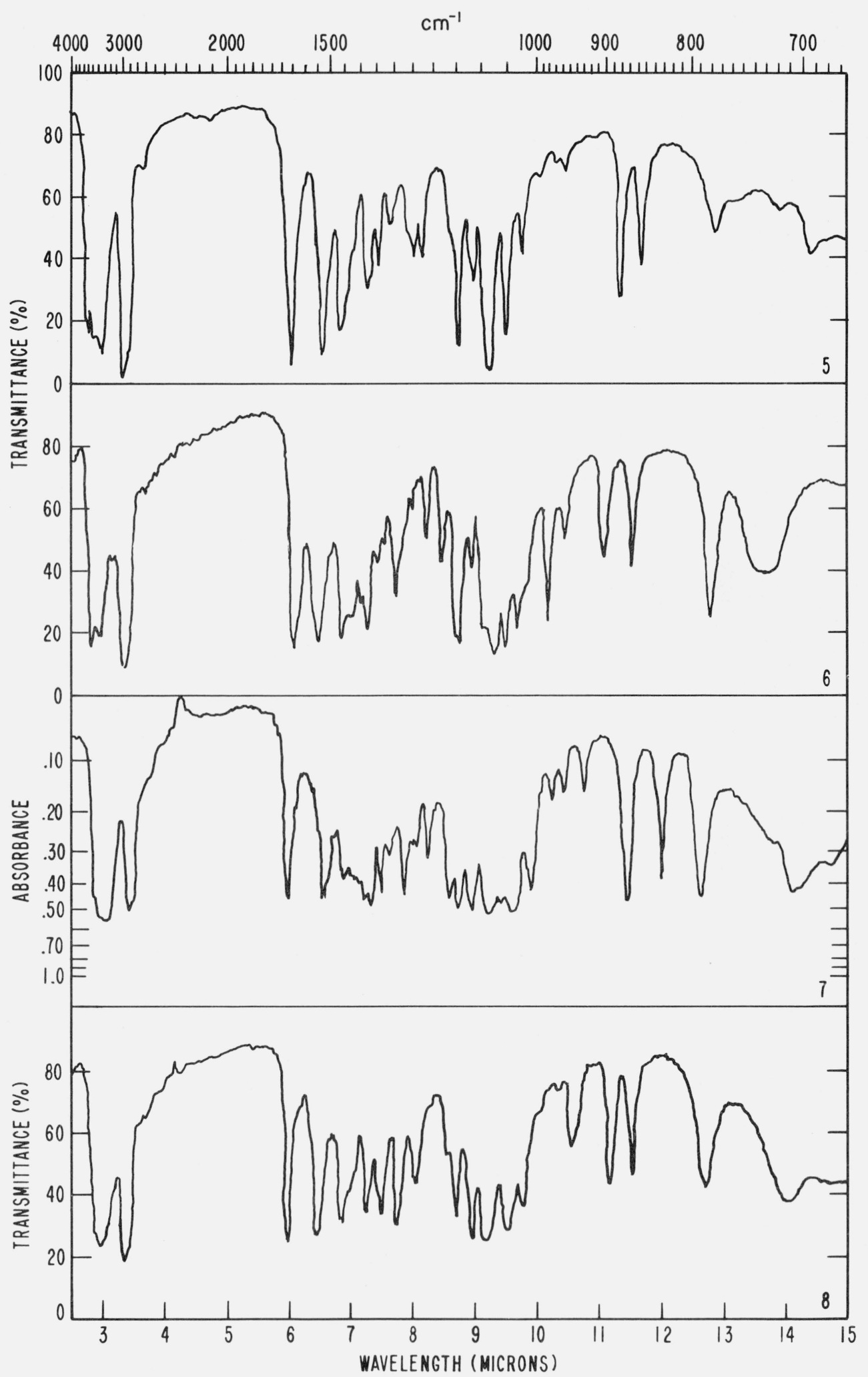

FigURE 1. Spectrograms of compounds in Nujol mulls. - Continued

5, $N$-acetyl- $\beta$-D-lyxopyranosylamine; $6, N$-acetyl-6-deoxy- $\beta$-L-mannopyranosylamine; $7, N$-acetyl- $\alpha$-D-galactopyranosylamine; $8, N$-acetyl- $\beta$-D-galactopyranosylamine. 


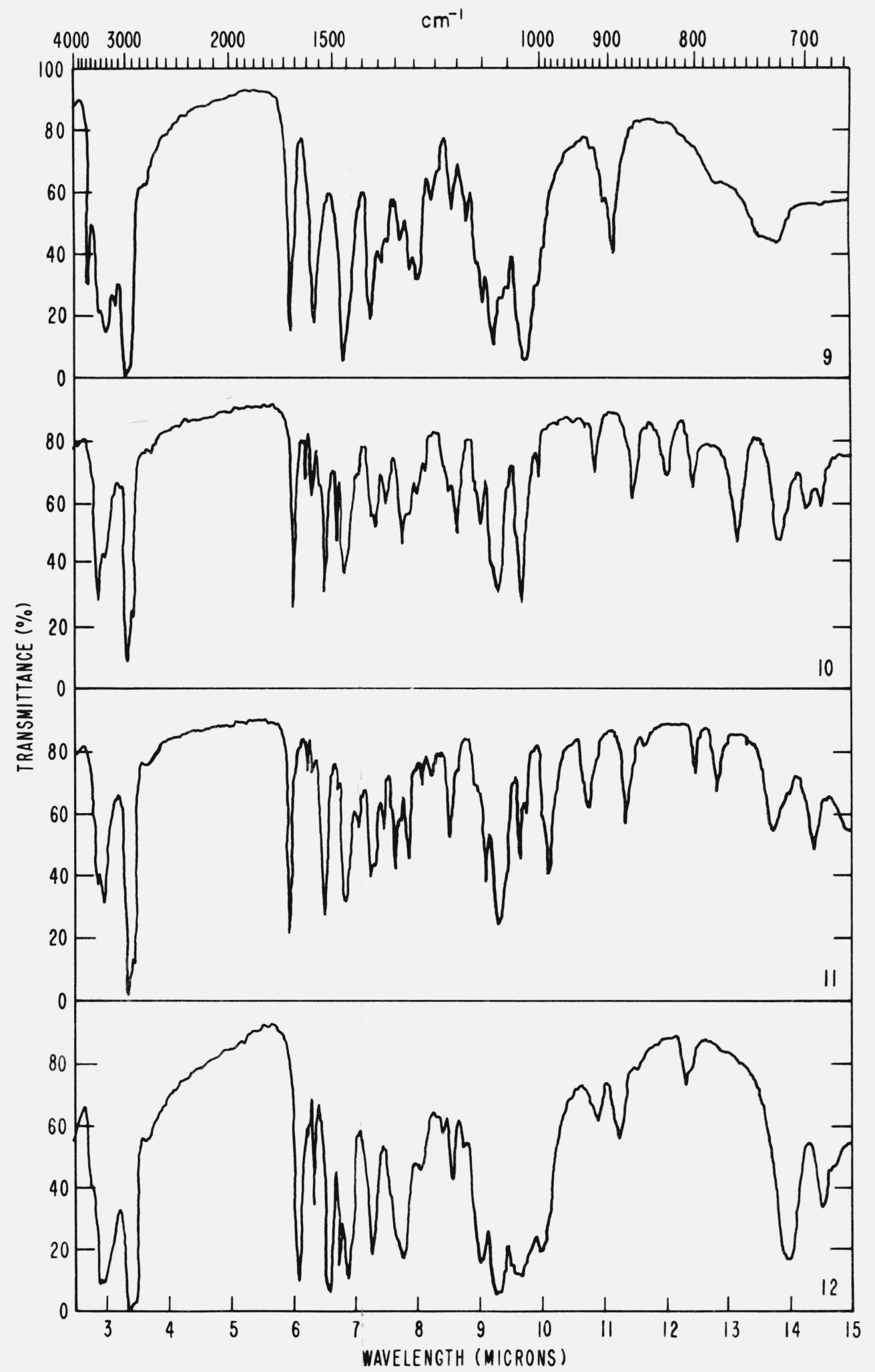

FigURE 1. Spectrograms of compounds in Nujol mulls.-Continued

9, $N$-propionyl- $\beta$-D-glucopyranosylamine; 10, $N$-benzoyl- $\beta$-D-lyxopyranosylamine; $11, N$-benzoyl- $\alpha$-D-arabinopyranosylamine; $12, N$-benzoyl- $\beta$-D-glucopyranosylamine. 


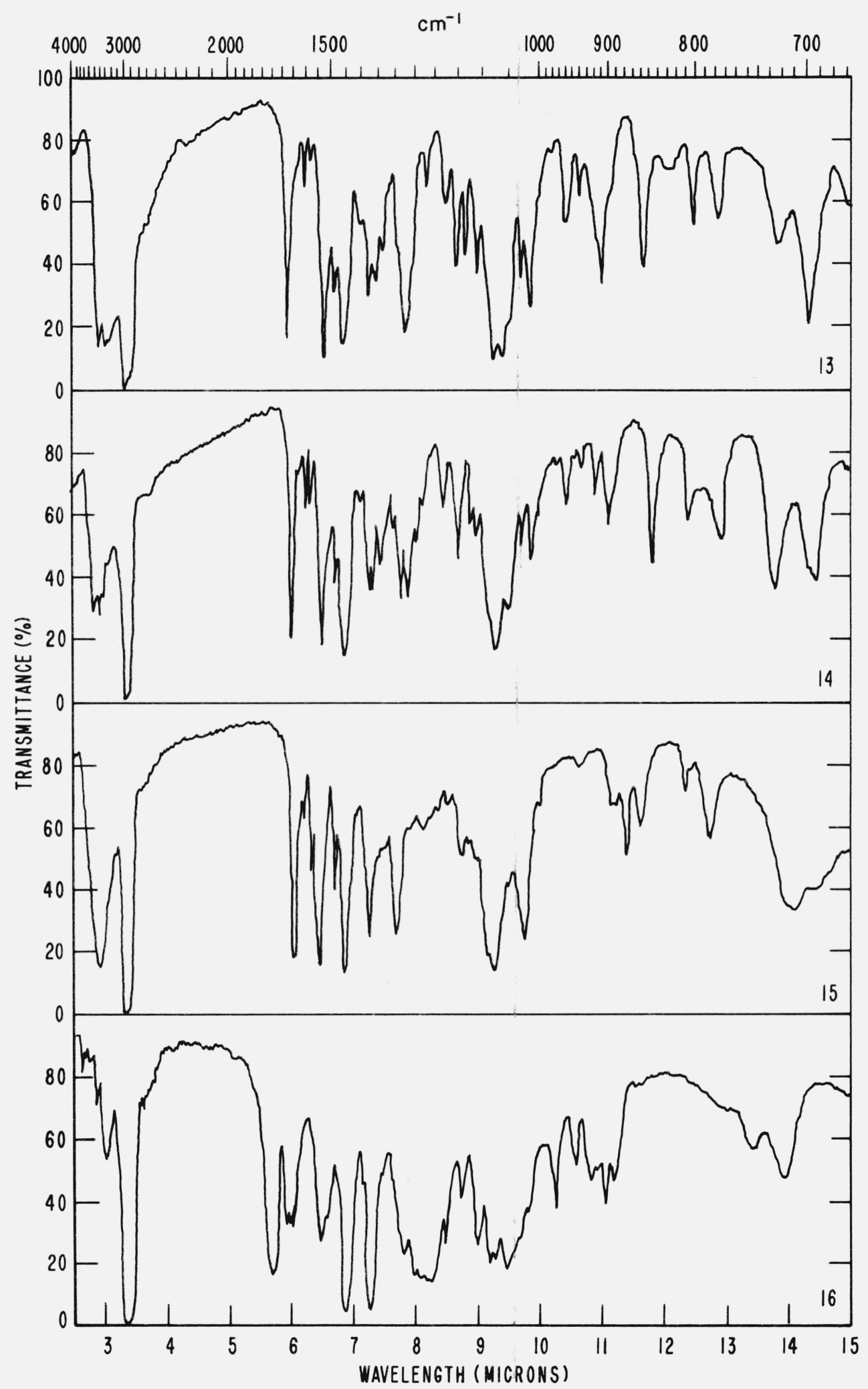

FiguRE 1. Spectrograms of compounds in Nujol mulls. - Continued

13, $N$-benzoyl- $\beta$-D-mannopyranosylamine; 14, $N$-benzoyl-6-deoxy- $\beta$-L-mannopyranosylamine; $15, N$-benzoyl- $\beta$-D-galactopyranosylamine; 16 , $N$-acetyl-2,3,4-tri- $O$-acetyl-6-deoxy- $\beta$-L-mannosylamine. 


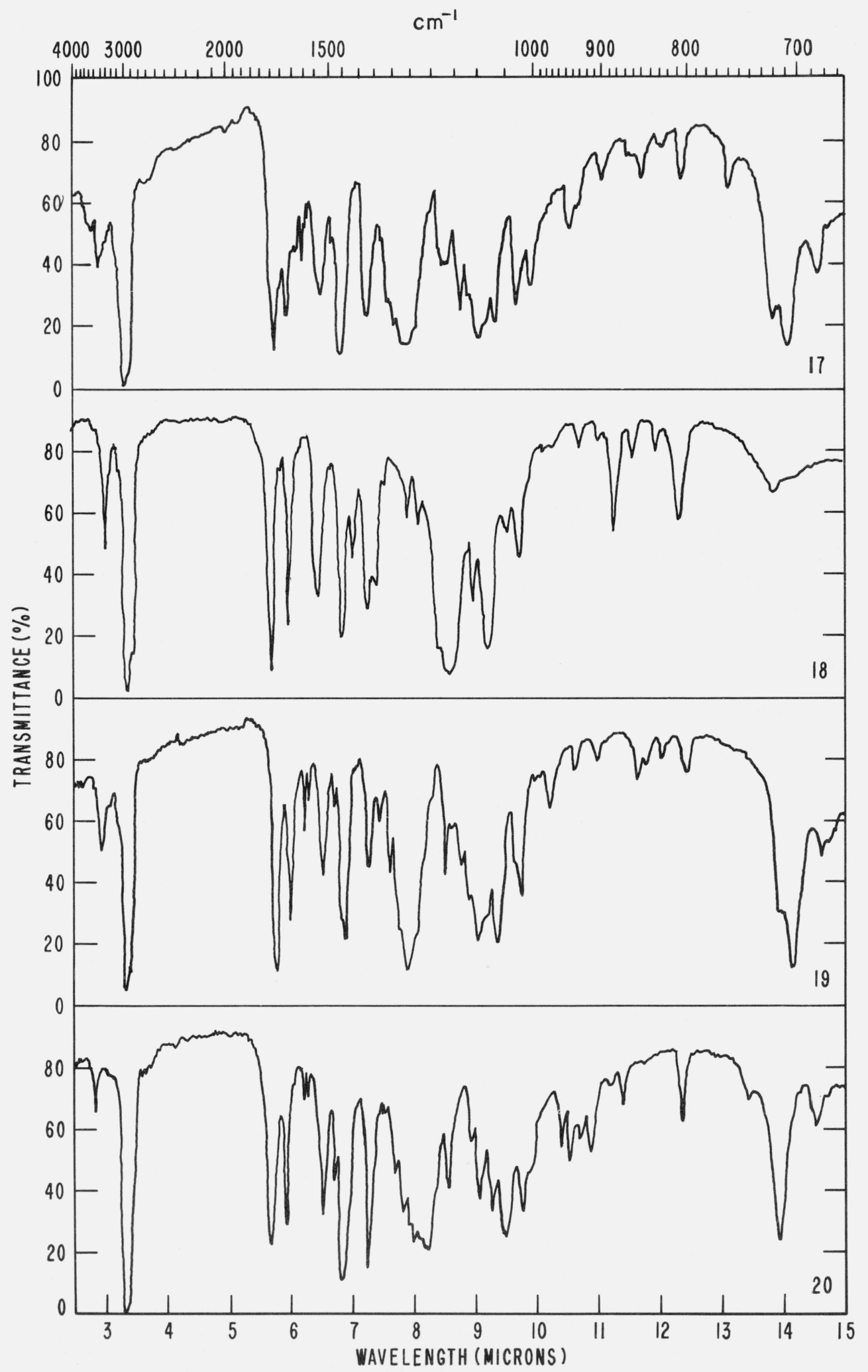

FigurE 1. Spectrograms of compounds in Nujol mulls. - Continued

1 7, $N$-acetyl-2,3,4-tri- $O$-benzoyl- $\alpha$-D-arabinosylamine; 18, $N$-propionyl-2,3,4,6-tetra- $O$-propionyl- $\beta$-D-glucosylamine; 19, $2,3,4,6$-tetra- $O$-benzoyl- $N$-propionyl- $\beta$-D-glucosylamine; 20, 2,3,4-tri- $O$-acetyl- $N$-benzoyl- $\alpha$-D-arabinosylamine. 


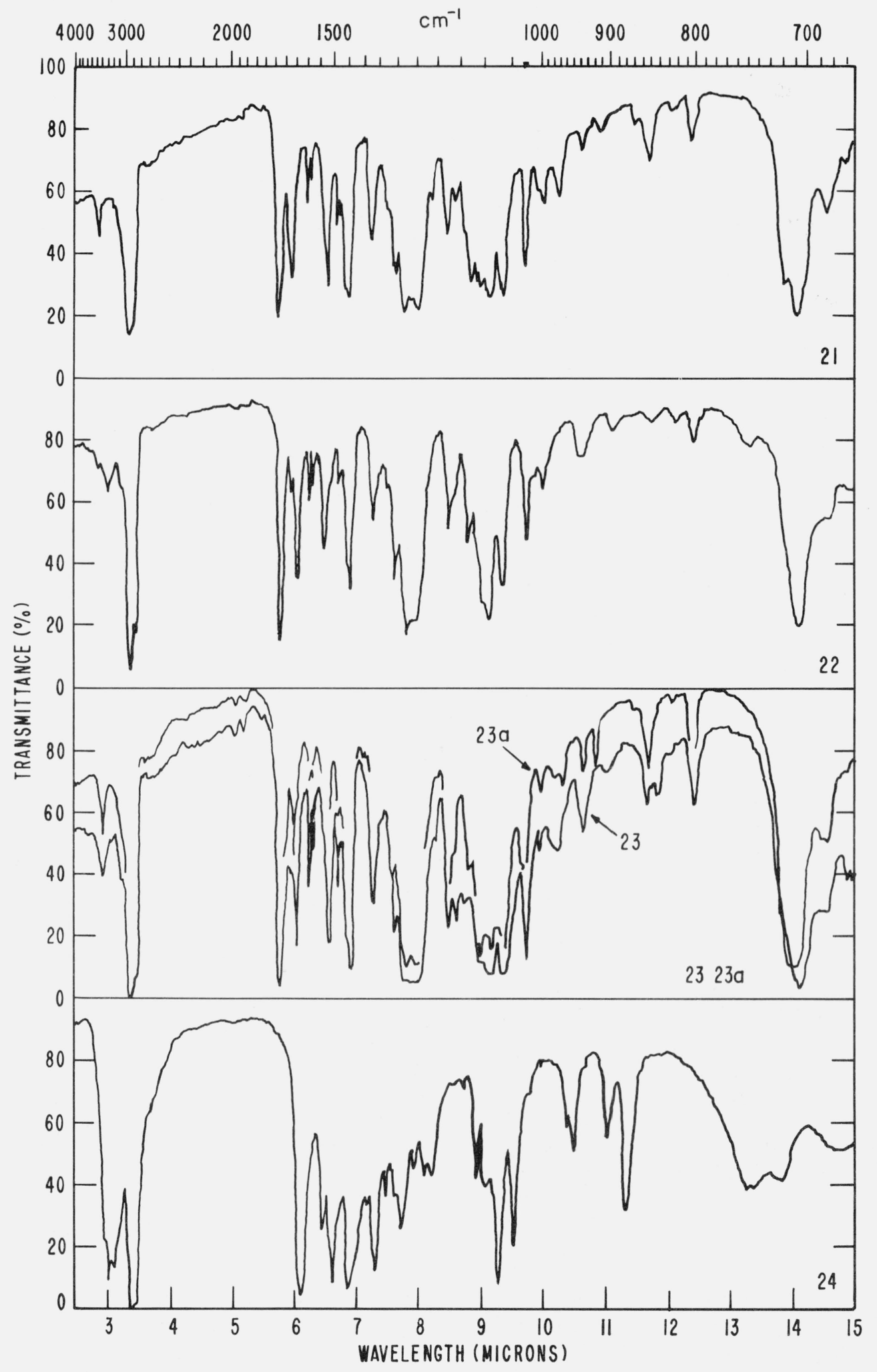

FIGURE 1. Spectrograms of compounds in Nujol mulls. - Continued

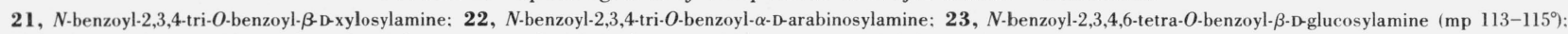
23 a, $N$-benzoyl-2,3,4,6-tetra- $O$-benzoyl- $\beta$-D-glucosylamine (mp 1849); 24, 1,1-bis(acetamido)-1-deoxy-D-erythritol. 


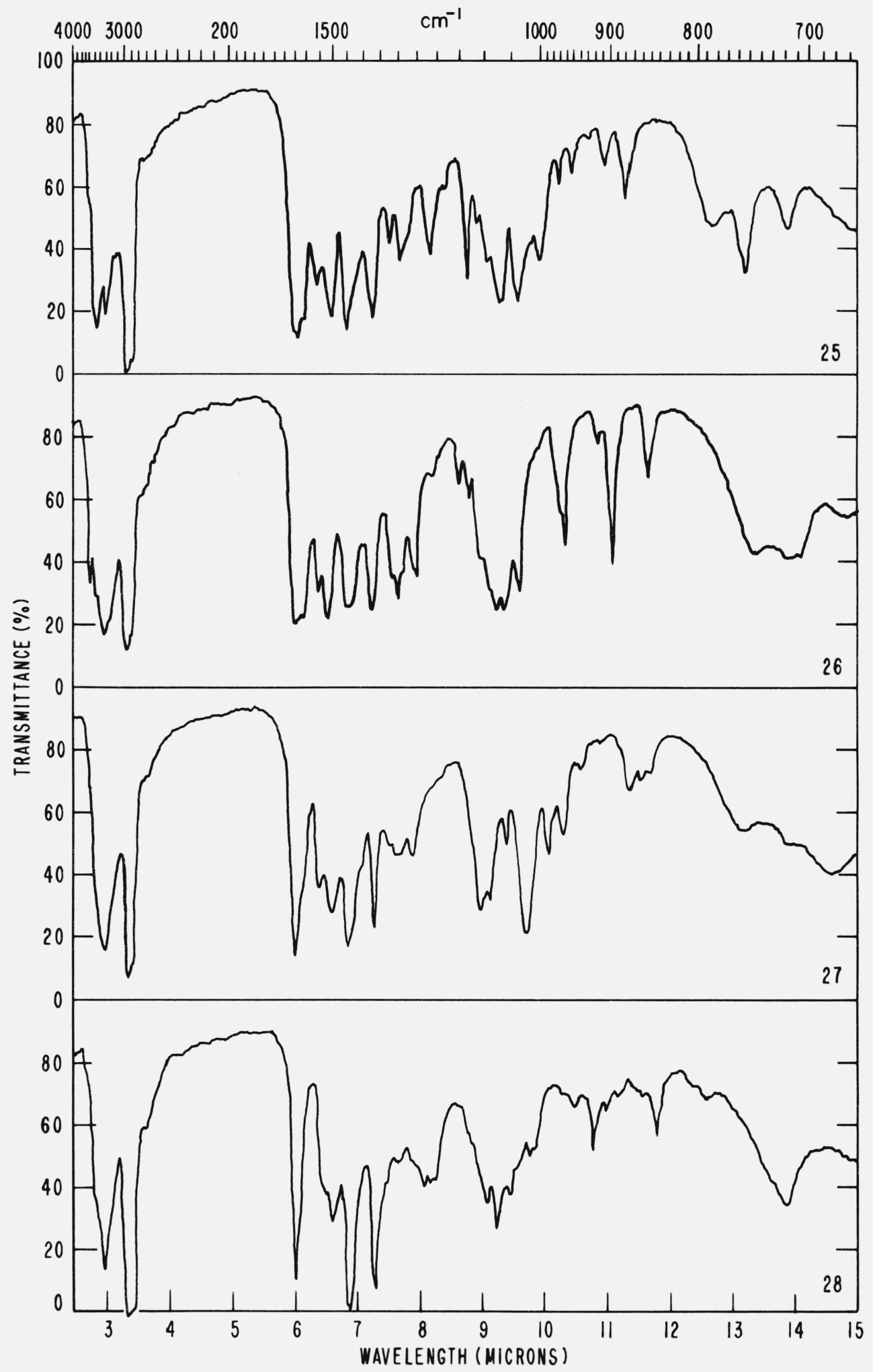

FigURE 1. Spectrograms of compounds in Nujol mulls.-Continued

25, 1,1-bis(acetamido)-1-deoxy-D-glucitol; 26, 1,1-bis(acetamido)-1,6-dideoxy-L-mannitol; 27, 1,1-bis(acetamido)-1-deoxy-D-galactitol; 28, 1-deoxy-1,1-bis(propionamido)-D-glucitol. 


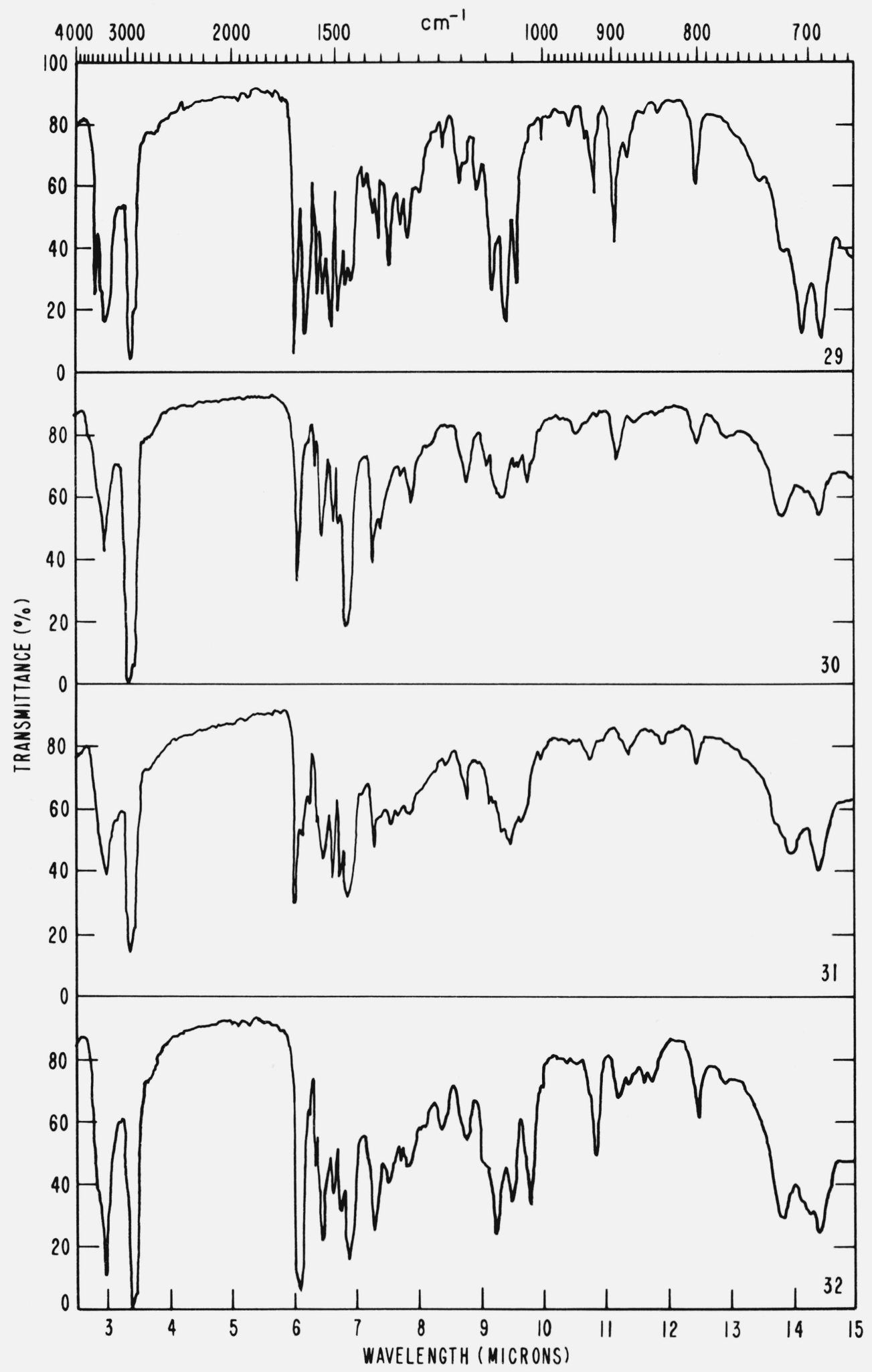

FigURE 1. Spectrograms of compounds in Nujol mulls.-Continued

29, 1,1-bis(benzamido)-1-deoxy-L-erythritol: 30, 1,1-bis(benzamido)-1-deoxy-Lrarabinitol; 31, 1,1-bis(benzamido)-1-deoxy-D-ribitol; 32, 1,1-bis(benzamido)-1-deoxy-D-glucitol 


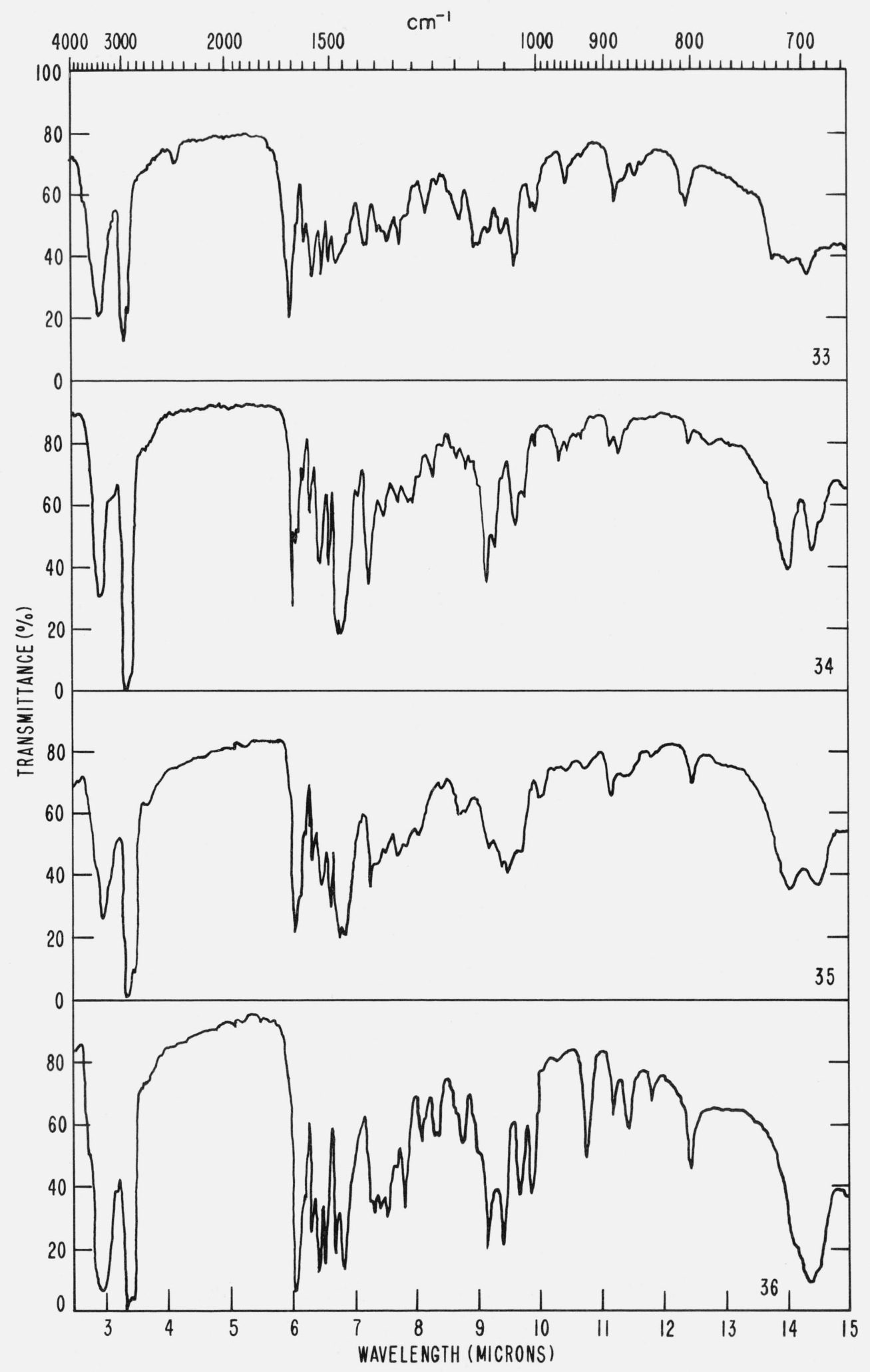

Figure 1. Spectrograms of compounds in Nujol mulls.-Continued

33, 1,1-bis(benzamido)-1,2-dideoxy-D-arabino-hexitol; 34, 1,1-bis(benzamido)-1-deoxy-D-mannitol; 35, 1,1-bis(benzamido)-1,6-dideoxy-L-mannitol; 36, 1,1-bis(benzamido)-1-deoxy-D-galactitol. 


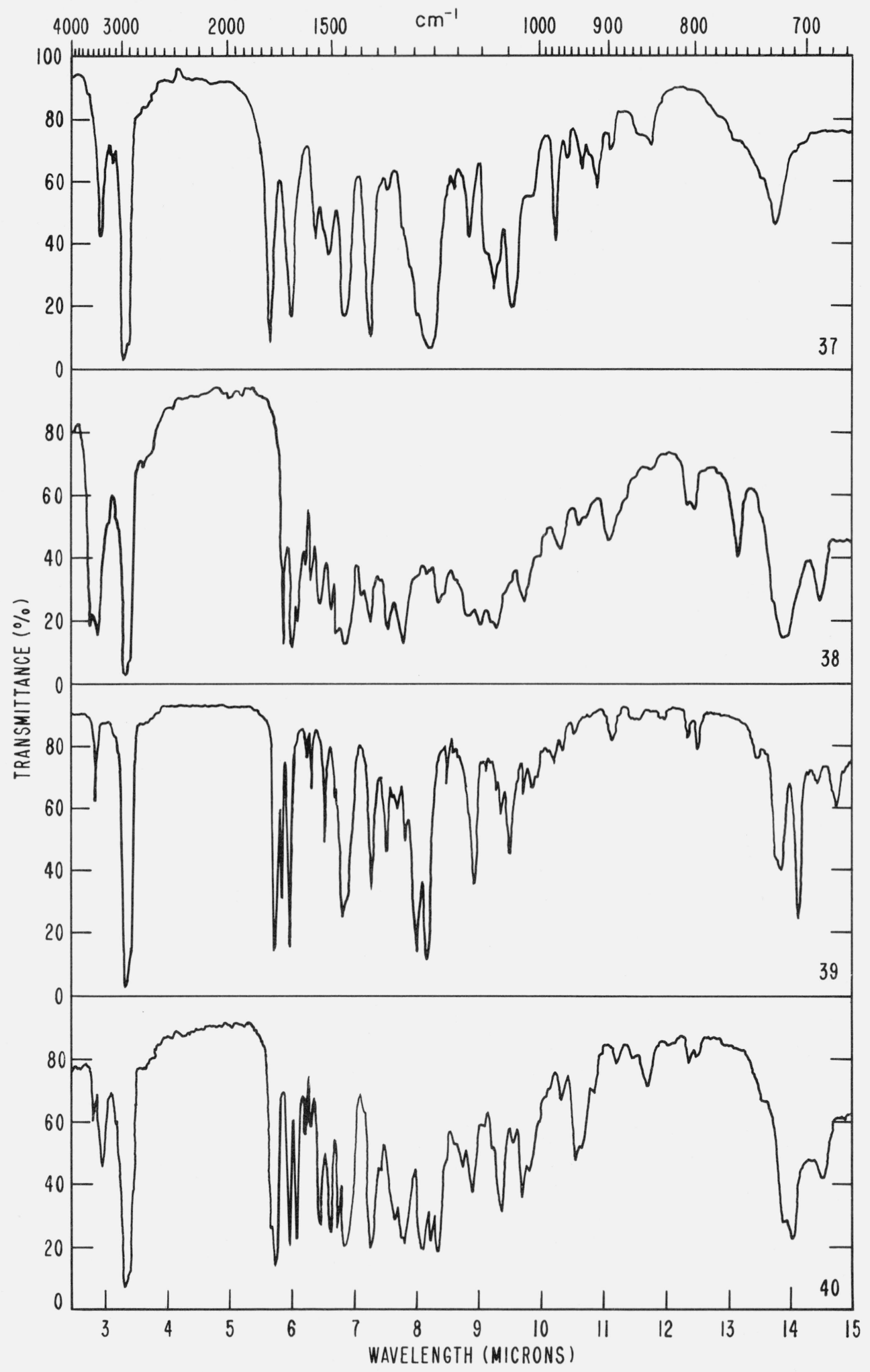

Figure 1. Spectrograms of compounds in Nujol mulls.-Continued

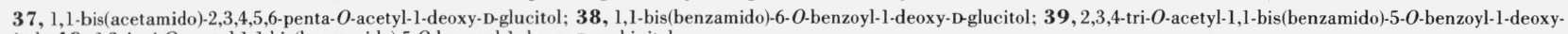
D-lyxitol: 40, 2,3,4-tri- $O$-acetyl-1,1-bis(benzamido)-5-O-benzoyl-1-deoxy-D-arabinitol. 


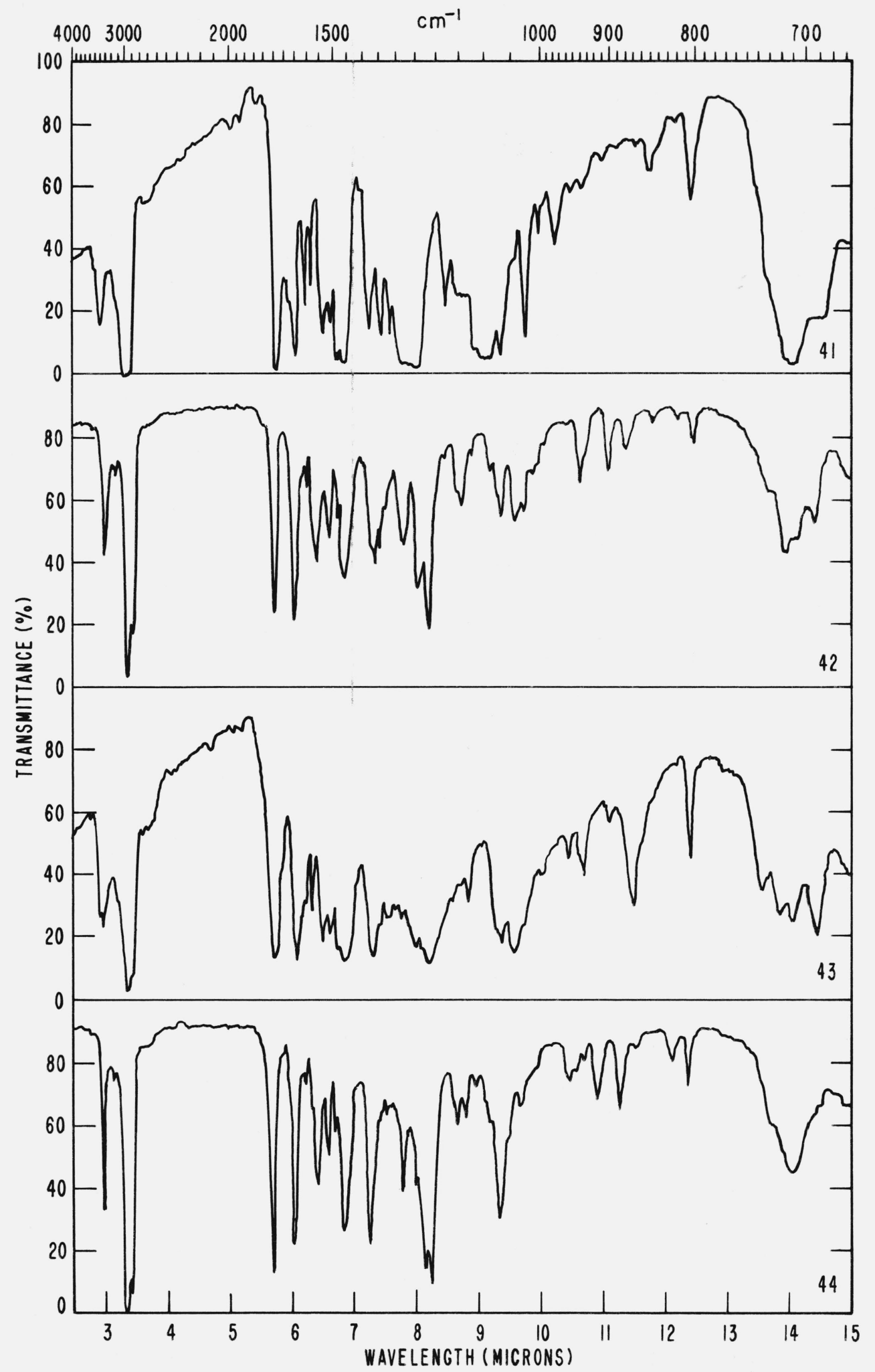

FigURE 1. Spectrograms of compounds in Nujol mulls. - Continued

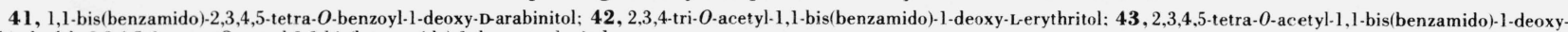
D-ribitol; 44, 2,3,4,5,6-penta- $O$-acetyl-1,1-bis(benzamido)-1-deoxy-D-glucitol. 


\section{References}

[1] H. S. Isbell, J. Res. NBS 57, 171 (1956) RP2707.

[2] R. S. Tipson and H. S. Isbell, J. Res. NBS 65A (Phys. and chem.) No. 1, 31 (1961).

[3] R. S. Tipson, J. Org. Chem. 26, 2462 (1961).

[4] S. A. Barker, E. J. Bourne, M. Stacey, and D. H. Whiffen, J. Chem. Soc. 1954, 171.

[5] S. A. Barker, E. J. Bourne, R. Stephens, and D. H. Whiffen, J. Chem. Soc. 1954, 3468.

[6] S. A. Barker, E. J. Bourne, R. Stephens, and D. H. Whiffen, J. Chem. Soc. 1954, 4211 .

[7] W. B. Neely, Advan. Carbohydrate Chem. 12, 13 (1957); see table II on p. 27 thereof.

[8] L. J. Bellamy, The infra-red spectra of complex molecules, 2d ed. p. 76 (John Wiley \& Sons, New York, N.Y.).

[9] H. S. Isbell and R. S. Tipson, J. Res. NBS 64A (Phys. and Chem.) No. 2, 171 (1960).

[10] G. P. Ellis, J. Chem. Soc. (B) 1966, 572.

[11] M. Stacey, R. H. Moore, S. A. Barker, H. Weigel, E. J. Bourne, and D. H. Whiffen, Proc. U.N. Intern. Conf. Peaceful Uses At. Energy, 2d, Geneva, 1958, Vol. 20, p. 251.
[12] S. A. Barker, E. J. Bourne, and D. H. Whiffen, Methods Biochem. Anal. 3, 213 (1956).

[13] H. Spedding, Methods Carbohydrate Chem. 1, 548 (1962).

[14] See, for example, C. N. R. Rao, Chemical applications of infrared spectroscopy, Academic Press Inc., New York, N.Y., 1963.

[15] H. Spedding, Advan. Carbohydrate Chem. 19, 23 (see p. 31) (1964).

[16] S. A. Barker and R. Stephens, J. Chem. Soc. 1954, 4550.

[17] R. S. Tipson, H. S. Isbell, and J. E. Stewart, J. Res. NBS 62 , 257 (1959) RP2960.

[18] R. S. Tipson and H. S. Isbell, J. Res. NBS 66A (Phys. and Chem.) No. 1, 31 (1962)

[19] L. M. J. Verstraeten, Anal. Chem. 36, 1040 (1964); Carbohydrate Res. 1, 481 (1966).

[20] P. Nanasi and P. Cerletti, Gazz. Chim. Ital. 92, 576 (1962); P. Nanasi, E. Nemes-Nanasi, and P. Cerletti, ibid. 95, 966, 975 (1965). 